\title{
Water Requirement for Maize Crop Under Climate Change in Mirab Abaya Woreda, Southern Ethiopia
}

\author{
Alem Getachew Legesse \\ Department of Meteorology and Hydrology, Arba Minch University, Arba Minch, Ethiopia \\ Email address: \\ alemgech21@gmail.com

\section{To cite this article:} \\ Alem Getachew Legesse. Water Requirement for Maize Crop Under Climate Change In Mirab Abaya Woreda, Southern Ethiopia. \\ International Journal of Energy and Environmental Science. Vol. 6, No. 3, 2021, pp. 50-66. doi: 10.11648/j.ijees.20210603.11
}

Received: March 16, 2021; Accepted: May 21, 2021; Published: May 31, 2021

\begin{abstract}
Climate change is a topic of discussion worldwide including in Ethiopia. Ethiopia is one of the country's most vulnerable to the impacts of climate variability and change on agriculture. This study investigates were to examine crop water requirements under climate changes scenarios for maize crop at Mirab-abaya woreda which is situated in $6.18 \circ \mathrm{N}$ latitude and $37.77 \circ \mathrm{E}$ longitude. Dynamically downscaled climate model outputs were obtained from the CORDEX-Africa program for (RCP) Representative Concentration Pathway of both scenarios which were used for future climatic conditions of the future periods; (2021 - 2050). The projected data was quality checked, biased corrected and model performance was evaluated. Mann Kendall's trend detection and Sen.'s slope estimator were used by XLSTAT software to evaluate the trends of projection and to detect changes. Hargreaves method was used to estimate current and future crop evapotranspiration of Maize. The result for observed and future revealed that the maximum and minimum temperatures increase in all time horizons. However, Projections of future rainfall suggest that annual rainfall decreases in both scenarios, the current and future potential evapotranspiration show that increasing trend in both cases except the observed Mirab-abaya station.
\end{abstract}

Keywords: Trend Analysis, Climate Change, Crop Water Requirement, CROPWAT

\section{Introduction}

Water is important for all forms of life and is becoming a scarce natural resource in the future owing to climate variability/change. It is crucial for crop production and the best use of available water must be made for efficient crop production and high yields. The relationships between crop, climate, water, and soil are complex and many biological, physiological, physical, and chemical processes are involved. Knowledge of reliable estimates of water required by different crops in a given set of climatological conditions of a region is a great help in rational utilization of irrigation water for irrigation scheduling, planning of irrigation schemes, and effective design of water-saving and management systems. The average global surface temperature is projected to increase by $1.4-3^{\circ} \mathrm{C}$ from 1990 to 2100 for low emission scenarios and $2.5-5.8^{\circ} \mathrm{C}$ for higher emission scenarios of greenhouse gases in the atmosphere [35]. Climate plays an important role in crop production. Crops growth periods, crops water requirements and irrigation scheduling for crops are dependent on weather conditions in a site [20].
Climate change refers to the deviation of climate/ atmospheric conditions over time from its long-term average conditions naturally or as a result of human activity and this change can have an impact on both globally as well as regionally thus impacts are flood, drought, land Slides, Hurricanes. Climate change has become one of the great challenges to the development of countries. It is now affecting agriculture and food production worldwide. There is evidence of declining crop yield due to climate change in many countries [38].

This challenge appears to be more devastating in the case of low-income countries. This is partly because of the high vulnerability of poor countries to climatic shocks due to their limited capacity to adapt and that agriculture accounts for a larger fraction of their economy and agriculture in these countries is climate-sensitive partly because of generally already high temperature and that it is largely rain-fed. As a result, significant proportions of people living in poor countries are facing the risks of food insecurity. Developing countries, including African countries, are vulnerable to climate change due to an increase of stresses such as human 
population, water scarcity, land degradation, and food insecurity [29; 51].

Agriculture is highly dependent on climate conditions and therefore subjected to change, with obvious impacts on food security. Changing environmental conditions such as rising temperatures,

Changing precipitation patterns, and an increase of extreme weather events seriously affect agricultural productivity, as vulnerability increases and even farming viability [14].

Ethiopian agriculture is characterized by extreme dependence on rainfall, low use of modern agricultural inputs, and low output levels [4]. More than $85 \%$ of livelihood in Ethiopia is dependent on rainfed agriculture that renders them much vulnerable to climate variability and change [55]. The majority of the Ethiopian population is dependent on rain-fed agriculture, but the agricultural production and productivity showed a declining trend from the 1960s onwards [17], due to changes in rainfall conditions which have a direct and immediate impact on the performance of the agricultural sector as well as on the country's total GDP [16].

General objective

The major aim of this study is to determine crop water requirements under climate change scenarios.

Specific objectives

To analyze the historical and future trend of precipitation, temperature, and evapotranspiration over Mirab-abaya.

To estimate crop water requirement for maize of Mirab-abaya.

To evaluate future crop water requirement of Maize under climate change scenarios for the 2050s.

Significant of the Study

The importance of the study is to indicate ways of maximizing Maize productivity in the Study area, to suggest ways how to increase awareness of the community about the impact of climate change on Maize production, to help agricultural sectors to take action for the consequence of climate change and increasing readiness before their effect. The findings of this study might be used in the future by different governmental and non-governmental organizations,

Researchers, and other bodies who work on maximizing Agricultural production in the study area as reference material.

Limitation of the study

Using uniformly distributed meteorological stations with long years of data records provide important information compared to the limited number and years of data records especially for water requirement under climate change but, in the study area, few meteorological stations are available which are used for analysis based on their data availability.

Location

The study was carried out in Mirab-abaya Wereda, Gamogofa Zone, Southern Nations, Nationalities, and People's Region of Ethiopia, located between $6.15^{\circ} \mathrm{N}$ to $6.36^{\circ} \mathrm{N}$ latitude and $37.35^{\circ} \mathrm{E}$ to $37.56^{\circ} \mathrm{E}$ longitude. Mirab-abaya bordered Wolaita Zone [Humbo Wereda and Boreda Wereda] from the north, Arbaminch Zuriya Wereda from the south, Lake Abaya from the east, and Chencha
Wereda from the west (Figure 1).

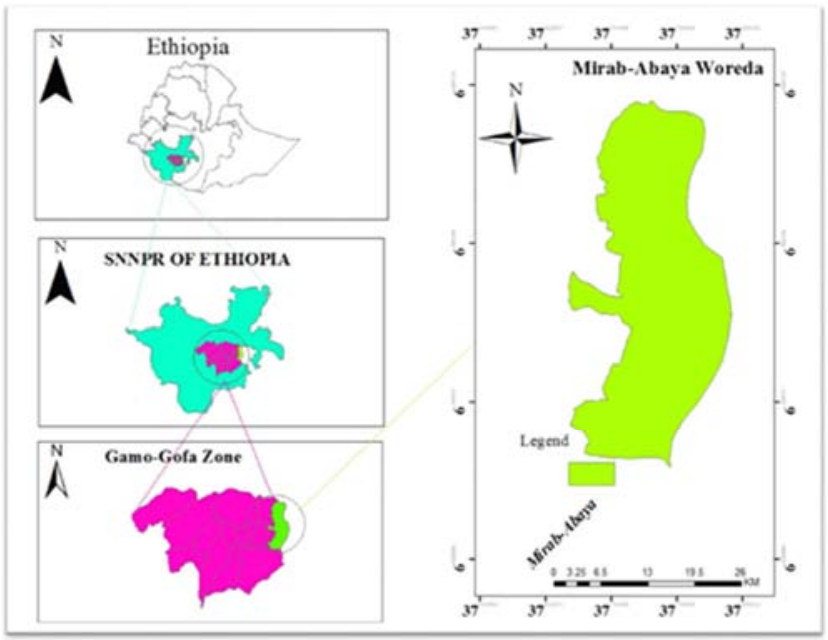

Figure 1. Map of the study area.

Crop data

The crop data such as Kc value, root depth, critical depletion, maximum crop height, and the lengths of crop development stages those crop data were collected from FAO no. 562000.

A general framework of the study

The major steps followed in this study were summarized by a flowchart in Figure 2. Following data collection, process and quality test of such as in filling the missed data of observed data, homogeneity test, consistence test, bias correction, and then data organization and preparation for Crop model input has been performed.

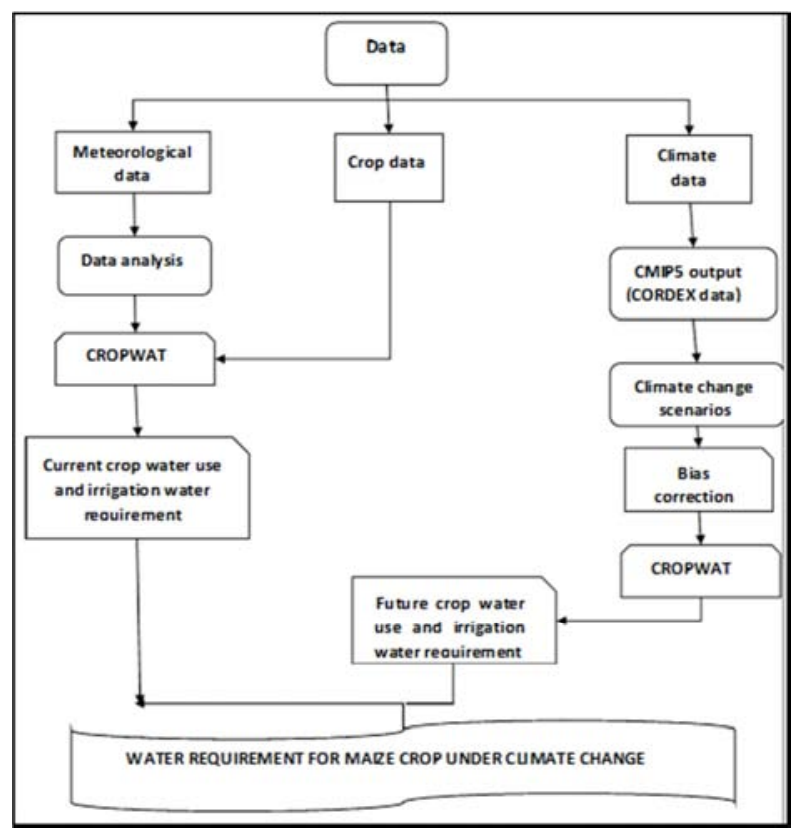

Figure 2. General framework of the study.

Meteorological data

Daily rainfall, minimum and maximum temperature, wind, relative humidity, and sunshine hours were collected from the National Meteorological Agency of Ethiopia. 
Table 1. Stations Information.

\begin{tabular}{lllll}
\hline Station & Long & Lat & Type of data & \% of missing \\
\hline M/abaya & 37.6 & 6.28 & RF, wind, RH, sunshine hours, Tmax and Tmin & 4.94 \\
Chencha & 37.57 & 6.25 & RF & 8.59 \\
A/minch & 37.77 & 6.05 & RF, wind, RH, sunshine hours, Tmax and Tmin & 1.36 \\
\hline
\end{tabular}

Climate data

Daily climate parameters such as precipitation, maximum and minimum temperature were collected from regional climate datasets with the recently developed scenarios collected from the Canadian climate center. The climate data used corresponded to the Canadian Earth System Model2 (CanEM2) climate model which is downscaled outputs by CORDEX Africa at a grid resolution of 0.50 by 0.50 .

\section{Methods}

Missing data filling techniques

Analysis of climate change trends and their impact on crop productivity simulation needs long-term time series filling of missed data. The missed data of meteorological stations were completed by using stations that are located in the nearby study area. For this research, the Normal ratio method was used to fill the gaps in the missing records of daily rainfall data for stations in which the missed data record is more than $10 \%$ from the total observed period.

Normal Ratio Method

This method is used if any surrounding gauges have the normal annual precipitation exceeding $10 \%$ of the considered gauge. This weighs the effect of each surrounding station [43]. The missing data are estimated by,

$$
\mathrm{P}_{\mathrm{x}}=\frac{N_{x}}{n}\left[\frac{P_{1}}{N_{1}}+\frac{P_{2}}{N_{2}}+\frac{P_{3}}{N_{3}}+\cdots \ldots+\frac{P_{n}}{N_{n}}\right]
$$

$\mathrm{Px}=$ Estimate for the ungauged station $\mathrm{Nx}=$ Normal annual precipitation of $\mathrm{X}$ station $\mathrm{Pi}=$ Rainfall values of rain gauges used for estimation, $\mathrm{n}=$ No. of surrounding stations $\mathrm{Ni}=$ Normal annual precipitation of surrounding stations

Consistency test

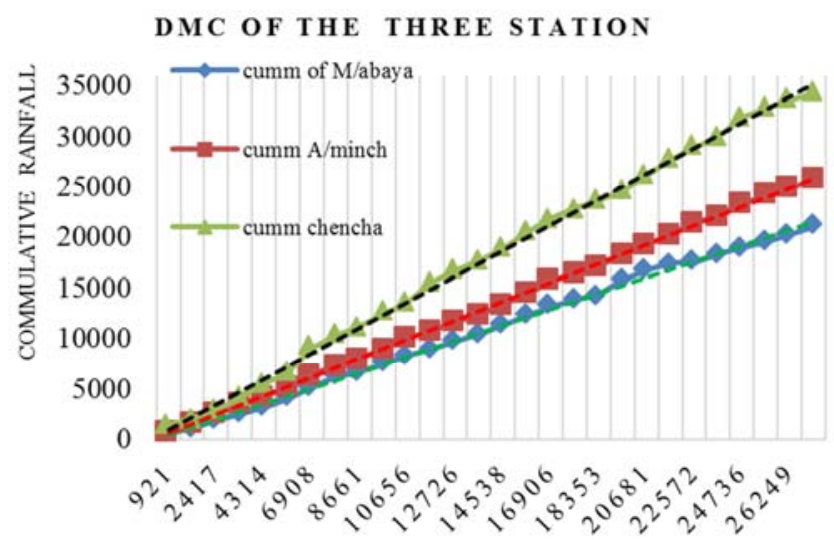

Figure 3. Double mass curve meteorological stations.

To detect possible errors checking the station for data quality using the appropriate method is crucial. Therefore, checking the consistency of individual stations, the data qualities concerning possible temporal variations or errors have been investigated by Double Mass Curve.

Double mass curve technique to ensure that any trends detected are due to meteorological cause and not to change in gage location, in exposure, or observational methods. If the change detected is not due to meteorological causes, a precipitation record can usually be adjusted by coefficients determined from the double mass curve.

In this study both Mirab-abaya, Arbaminch, and Chencha data are consistent in Figure 1.

Homogeneity test

Non-homogeneous data series for climate change impact assessment may amplify real climate variations. The collected data said to be homogenous if the measurements have been consistently done by the same method, with the same instrumentation, at the same time and place, and in the same environment [37]. Homogeneity of collected datasets was tested by RAINBOW software using frequency analysis. The methods designed to study the homogeneity of hydro-meteorological datasets are given below. Homogeneity restricts observations from the same population and bases on the cumulative deviations from the mean using the following equation.

$$
\mathrm{SK}=\sum_{i=1}^{k}\left(X_{i}-\bar{X}\right) \ldots \ldots \ldots \ldots \ldots K=1 \ldots \ldots n
$$

Where $\mathrm{Xi}$ is time series data and $\mathrm{X}$ the mean of data record data the initial value of $S(k=0)$ and last value $S(k=n)$ are equal to zero.

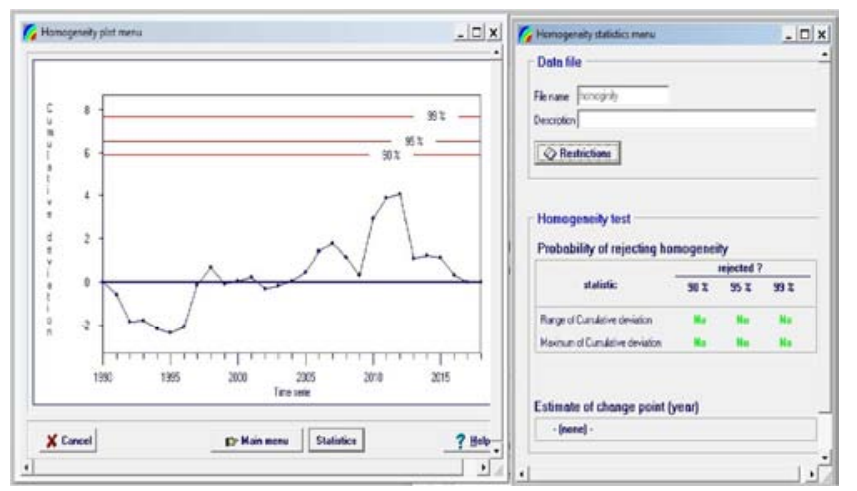

Figure 4. Homogeneity test plot and statistics of estimated change for Mirab-abaya station.

When plotting the SK's (sometimes called residual mass curves, changes in the mean are easily detected. For a time-series data record $\mathrm{Xi}$ above normal the SK increases, while for a record below normal SK decreases. For a homogeneous record, one may expect that the SK's fluctuate around zero since there is no systematic pattern in the 
deviations of $\mathrm{Xi}$ from their mean value. The rejection of homogeneity assures that the observations are from the same population and the statistical menu assures the probability of acceptance and rejection options. Therefore, the figure below showed the probability of rejecting the homogeneity test is accepted at all significant levels of Mirab-abaya station at (90, 95 , and $99 \%$ ) for both the ranges of cumulative deviation and maximum of cumulative deviation.

Further homogeneity tests of annual rainfall applied to other stations were given in Figure 2.

Bias correction method

Bias correction method applied for each daily precipitation and temperature dataset derived from Africa CORDEX to minimize the systematic statistical deviation of climate output data from the observational data before using for any future climate change projection. Methods to correct the biases in the climate model outputs to improve the realism of Global Circulation Model and Regional Climate Model (GCM/RCM) precipitation time series, based on statistical properties obtained from observed data taken from the same baseline period. When correcting for biases in climate model output, it is also important that changes in the frequency distribution of climatic variables are correctly represented. The bias correction made for precipitation and temperature in this study is as described below.

Power transformation

For this method, correction factors are computed from the statistics of the observed and simulated variables. The principle of this method shows the mean and standard deviation of the daily precipitation data becoming equal to those of the observed data $[33 ; 34]$.

$$
P^{*}=\mathrm{a} P^{b}
$$

Where $\mathrm{P}$ is the corrected value of precipitation, $\mathrm{b}$ is the scaling exponent which is computed until the coefficient of variation $(\mathrm{CV})$ of the RCM precipitation data set matches with that of the observed data sets. The constant ' $a$ ' is calculated using the mean of the transformed precipitation value is equal to the observed mean (i.e., ' $a$ ' and $b$ are the parameters obtained from calibration in the baseline period and subsequently applied to the projection period).

The bias correction for temperature differs from that of the precipitation because, bias correction method for precipitation uses power law while this method is not important for temperature as it is approximately a normal distribution [46].

Hence, the bias correction for temperature involves only shifting and scaling to adjust the mean and variance [46] and can be computed by:

$$
\text { Tcorr }=\text { Tobs }+\frac{\delta(T o b c)}{\delta(\operatorname{Trcm})}(\operatorname{Tr}-\mathrm{TRN})
$$

Where Tcorr is the corrected daily temperature; Trcm is the uncorrected daily temperature from the RCM model; Tobs is observed daily temperature; Tobs and Trcm are the mean temperature for observed and simulated datasets, respectively. Trend analysis

The WMO recommends the non-parametric Mann- Kendall trend test statistics for the assessment of trends in meteorological data [52]. This method was also used to detect changes in hydro-meteorological variables [22; 47; 54].

Because it is less sensitive to outliers and there is no assumption of statistical distribution as well as it reduces the chance of errors during statistical analysis which makes it robust $[22 ; 45]$. Based on this trend test, the null hypothesis (Ho) assumes that there is no trend in the time series data (i.e., the dataset is independent and ordered randomly) and this can be tested against the alternative hypothesis (H1), which assumes there is a trend in the time series data [40]. The total score for the datasets is the Mann- Kendall statistics, which is then compared to a critical value to test whether the trend in the hydrometeorological datasets is increasing, decreasing, or no trend can be evaluated. The first step is to determine the sign of the difference between consecutive sample results. Sign $(\mathrm{Xj}-\mathrm{Xi})$ is a function that implies that results in the value $-1,0$, or +1 based on the sign of $(\mathrm{Xj}-\mathrm{Xi})$ where $\mathrm{j}>\mathrm{i}$. Positive and negative values of $\mathrm{S}$ present an upward and downward trend [11] respectively. The function of $\mathrm{S}$ can be computed by:

$$
\begin{gathered}
\mathrm{S}=\sum_{i=1}^{n-1} \sum_{j=i+1}^{n} \operatorname{sign}\left(X_{j}-X_{i}\right) \\
\operatorname{Sign}\left(X_{j}-X_{i}\right)=\left\{\begin{array}{c}
-1, \text { if }\left(X_{j}-X_{i}\right)<0 \\
0, \text { if }\left(X_{j}-X_{i}\right)=0 \\
+1, \text { if }\left(X_{j}-X_{i}\right)>0
\end{array}\right\}
\end{gathered}
$$

Where "S" is the rating score (Mann - Kendall sum); „, $\mathrm{X}^{\prime \prime}$ is the observation value; $n$ " is the number of observation values in the time series, and are the sequential hydro-meteorological values in a month and $\mathrm{I}(\mathrm{j}>\mathrm{i})$ respectively. The value of $\mathrm{S}$ “+, and 0 " implies increasing, decreasing, and no trend, respectively. If ties (equal values) in the $\mathrm{X}$ values happen, the variance of $\mathrm{S}$ is computed by:

$$
\operatorname{Var}(\mathrm{S})=\frac{n(n-1)(2 n+5)-\sum_{i=1}^{m} t i(i)(i-1)(2 i+5)}{18}
$$

Whereas if ties have not occurred, the variance of Scan computes by:

$$
\operatorname{Var}(S)=\frac{n(n-1)(2 n+5)}{18}
$$

Where $m$ is the number of tied groups in the time series data and is the number of data points in the ith tied group. When $n$ greater than 10 , the standard normal $\mathrm{Z}$ test statistics are calculated by Mann-

Kendall statistic:

$$
\mathrm{Z}=\left\{\begin{array}{l}
\frac{1-s}{\sqrt{\operatorname{var}(s)}} \text { if } s<0 \\
0-- \text { if } s=0 \\
\frac{1-s}{\sqrt{\operatorname{var}(s)}} \text { if } s>0
\end{array}\right\}
$$

The test statistical $\mathrm{Z}$ is used to determine the significance trend. This test statistic is applied to test the null hypothesis (Ho). This means, if $|\mathrm{Z}|$ is greater than $\mathrm{Za} 2$; where $\alpha$ determines the selected significance level (for instance 5\% for the present 
study with Zo. o5 $2=$ Zo. 025=1.96) then Ho is rejected, implying that the trend is significant [39] Kendall's tau was used to measure the correlation between two samples and then used to analyze the strength of the relationships between the variables. The slope of linear trend is tested with non-parametric Sen"s slope method [22]. The slope of $n$ pairs of data points were estimated using the Sen"s slope estimator as:

$$
\mathrm{Q} i=\frac{(\mathrm{Xi}-\mathrm{Xi})}{(j-i)} \text { for } \mathrm{i}=1-\mathrm{N}
$$

Where and are data values at times $\mathrm{j}$ and $\mathrm{i},(\mathrm{j}>\mathrm{i})$ respectively. The median of this N value of Qi is Sen"s estimators of the slope. If there is only one data in each period, then $\mathrm{N}=\mathrm{n} \frac{(\mathrm{n}-1)}{2}$

Where $\mathrm{n}$ is the number of periods. The median of the $\mathrm{N}$ estimated slopes are obtained in the usual way, i.e., the $\mathrm{N}$ values of Qi are ranked by $\mathrm{Q} 1<\leq \mathrm{Q} 2 \leq \ldots$ Qn-1 $\leq$ Qn and Sen"s Estimator $=\frac{\mathrm{Q}(\mathrm{n}-1),}{2}$ if $\mathrm{N}$ is odd or $=\frac{\frac{Q n}{2}+=\frac{\mathrm{Q}(\mathrm{n}-1),}{2}}{2}$ If $\mathrm{N}$ is even. The positive value of Qi suggests an upward or increasing trend while a negative value of Qi shows a downward or decreasing trend in the time series. Overall the two-tailed probability (P- values) was calculated using XLSTAT statistical software and then compared at a 5\% significance level to observe the trend of variables for this study

Crop Water Use Estimation

Estimating evapotranspiration (ETO) is one of the first important steps for calculating crop water requirements in the given location. The rationalization of water consumption in the agricultural fields under current and future climate conditions has economic importance. Quantification of reference evapotranspiration for short grass is necessary in the context of many issues, for example, crop production, management of water resources, scheduling of irrigation for Rainfall shortage area. Since, direct measurement of referable (ETO) for short grass is difficult, time- consuming, costly, the most important practical approach would be to estimate from ETo, involving equations ranging from the most complex energy balance method requiring detailed climatological data [1] Among them, FAO-56 based on the pen-man Monteith (PM) method is currently used and considered to be the standard method. However, the major drawbacks of the FAO-56 PM method, method require the availability of air temperature, relative humidity, wind speed, and solar radiation which could not be easily available in a given location including the study area. Where the quality of data and difficulty in gathering all of the necessary weather parameters can present. Therefore, above mentioned limitation and it's quite simplest including only two input parameters, this particular study conducted the Hargreaves method to estimate evapotranspiration. The equation for computation of Evapotranspiration by [24].

$$
\begin{gathered}
\mathrm{ET}_{\mathrm{O}}=0.0023\left(\mathrm{~T}_{\text {mean }}+17.8\right)(\mathrm{T} \max -\mathrm{T} \min ){ }^{0.5} \mathrm{Ra} \\
T_{\text {mean }}=\frac{T_{\text {max }}+T_{\text {min }}}{2}
\end{gathered}
$$

$$
\begin{gathered}
\mathrm{Ra}=\frac{24(60)}{n} G s c d r\left[\left(\omega^{s} \sin \varphi \sin \delta\right)+\cos \varphi \cos \delta \sin \omega^{s}\right] \\
d r=0.033 \cos \left(\frac{2 \pi}{365 * j}\right) \\
\omega^{s}=[-\tan \varphi \tan \delta] \\
\delta=0.409 \sin \left(\frac{2 \pi}{365 * j-1.39}\right) \\
\varphi(\text { radians })=\frac{\pi \varphi}{180}(\text { decimal degress })
\end{gathered}
$$

Where, $\mathrm{Ra}=$ Extraterrestrial radiation in the hour or shorter period $\{\mathrm{MJ} \mathrm{m}-2$ hour-1 $\}, \mathrm{J}=$ Number of Julian day in the year between 1 January and 365 or 366,=Latitude of the stations, Gsc is solar constant $=0.0820 \mathrm{MJ} \mathrm{m}-2 \mathrm{~min}-1$ and $\mathrm{dr}=$ Inverse relative distance Earth-Sun International Commission on irrigation and drainage (ICID) (2000) defined the crop water requirement $(\mathrm{ETc})$ as the total water needed for evapotranspiration from planting to harvest for a given crop in a specific climate regime. FAO (2002) and [1] calculated ETc from ETo and $\mathrm{KC}$ (Crop coefficient) under standard conditions that represent the water loss from a disease-free, well-fertilized crop, grown in a large field; under optimum soil water conditions achieves full production potential under given climatic conditions. Considering this definition and FAO approach, the crop water requirement for the study area was determined using the following formula and Average monthly ETO was calculated using daily weather data of FAO-56 using the Hargreaves method to assess the future water availability and shortage for a crop at critical stages to schedule the deficit irrigation

$$
\begin{aligned}
\mathrm{ETc} & =\frac{\text { ETo }}{K c} \\
\mathrm{Kc} & =\frac{\text { ETo }}{E T c}
\end{aligned}
$$

In the formula, ETc is the daily actual crop evapotranspiration ( $\mathrm{mm}^{*}$ day'1), ETo is the daily reference evapotranspiration ( $\mathrm{mm} /$ day-1) and $\mathrm{Kc}$ is the crop coefficient.

\section{Results and Discussions}

Trends of Observed Meteorological Data

Precipitation

The MK test statistic was applied to the annual rainfall pattern of three stations (Table 2 and Figure 5). The result of the MK test showed that decreasing trends in annual precipitation at the two representative meteorological rainfall stations and an increasing trend for Arbaminch meteorological rainfall stations, but, insignificant trends were observed in annual precipitation, and the change magnitude was found generally higher in Arbaminch station than the two stations (Mirab-abaya and Chencha). The P-values of all the three stations were greater than the significant level $(5 \%)$ and it changed by the magnitude of (1.042, 0.294, and-7.551mm/year) in Arbaminch, Mirab-abaya, and Chencha rainfall stations, respectively. This implies there was a downward negative and positive trend in annual rainfall for 
Mirab-abaya and Chencha but, there was an upward positive trend in annual rainfall for Arbaminch station, which insignificantly decline at a 5\% confidence level in two stations and insignificantly upward at 5\% confidence level. The rainfall distribution over Mirab-abaya woreda has been found in non-stationary time series with a trend in the past 28 years in all rainfall stations. The results of trend analysis in precipitation are in agreement with earlier studies It is good agreement with [2], increasing in temperature along with reduced precipitation likely to result in the loss of agricultural land in the region due to decreased soil moisture, increased aridity, increased salinity, and groundwater depletion.

Table 2. Mann- Kendal trend test and statistical summary of annual rainfall at three stations.

\begin{tabular}{lllll}
\hline \multicolumn{2}{l}{ Rainfall (mm) } & & & \\
\hline Station & Kendall's tau & S & Sen.'s slope & p-value \\
\hline M/abaya & 0.005 & 2.000 & 0.294 & $0.984 \mathrm{~ns}$ \\
A/minch & 0.037 & 14.000 & 1.042 & $0.799 \mathrm{~ns}$ \\
Chencha & -0.111 & -42.000 & -7.551 & $0.422 \mathrm{~ns}$ \\
\hline
\end{tabular}
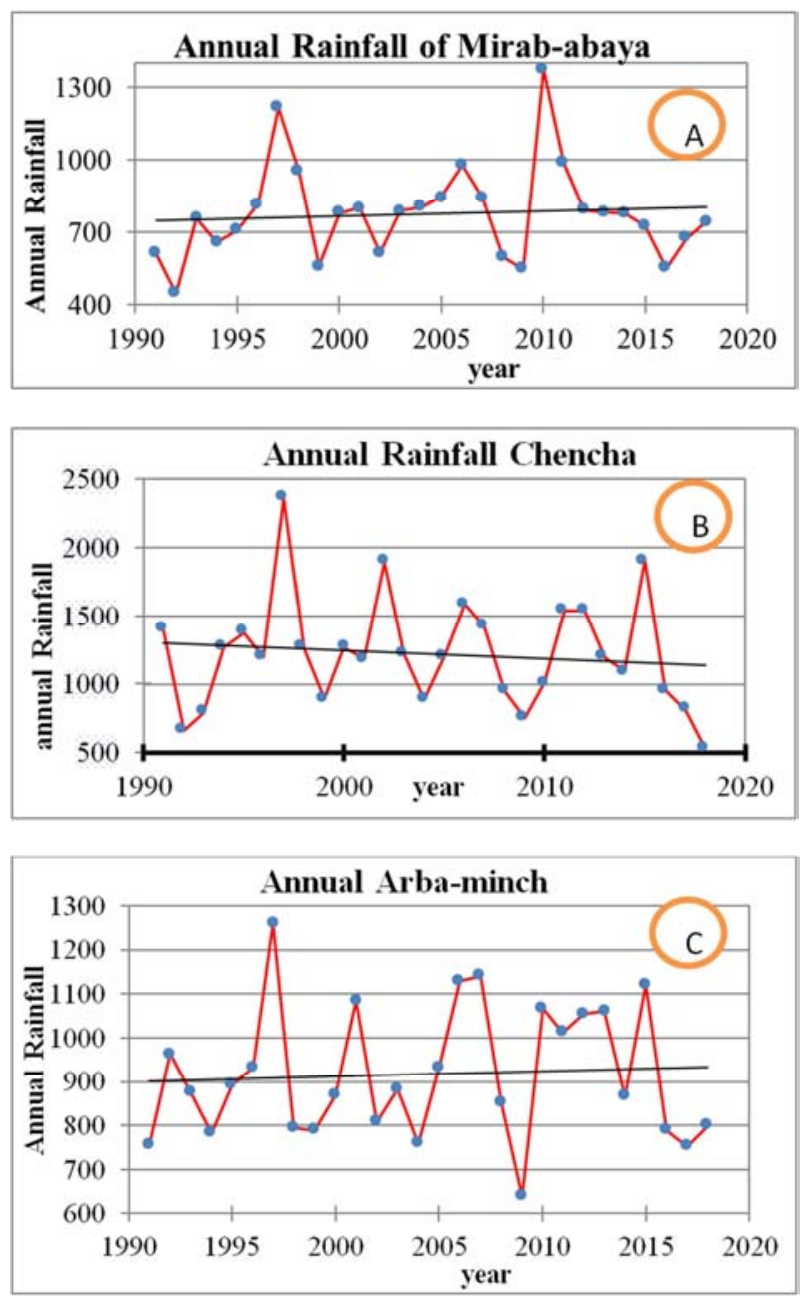

Figure 5. Observed long-term annual rainfall trend distribution of stations.

Temperature

For the temperature data recorded from the two stations (Mirab-abaya and Arbaminch), the average annual value was analyzed by using the MK test. The result shows that there has been an increasing trend of the average annual temperature at both stations as the computed p-value is lower than the significance level $\alpha=0.05$, one should reject the null hypothesis H0. It implies that the MK test is statistically significant for the average temperature, but, the p-value is greater than the significance level $\alpha=0.05$, one should reject the null hypothesis H0. However, the average annual temperature increasing trend was found statistically non-significant as the computed p-value is greater than the significance level $\alpha=0.05$, one cannot reject the null hypothesis (H0) as Summarized in Table 3 for each station both maximum and minimum temperature respectively indicates a warming trend. Also, the magnitude of average maximum temperature has increased to $0.013^{\circ} \mathrm{C} /$ year, and $0.026^{\circ} \mathrm{C} /$ year in Mirab-abaya and Arbaminch station, respectively, the minimum temperature increased at a rate of 0.081 , and $0.023^{\circ} \mathrm{C} /$ year at Mirab- abaya and Arbaminch stations respectively. The same trend of maximum and minimum temperatures was shown in Figure 15.

Table 3. Mann- Kendal trend test and statistical summary of annual maximum temperature (A) and annual minimum temperature (B).

\begin{tabular}{|c|c|c|c|c|}
\hline station & Kendall's tau & $\mathbf{S}$ & Sen.'s slope & P-value \\
\hline \multicolumn{5}{|c|}{ (A) Maximum Temperature } \\
\hline M/abaya & 0.153 & 58.000 & 0.013 & $0.263(\mathrm{~ns})$ \\
\hline $\mathrm{A} / \mathrm{minch}$ & 0.333 & 126.000 & 0.026 & $0.013 *$ \\
\hline \multicolumn{5}{|c|}{ (B) Minimum Temperature } \\
\hline M/abaya & 0.593 & 224.000 & 0.081 & $<0.0001^{*}$ \\
\hline $\mathrm{A} / \mathrm{minch}$ & 0.190 & 72.000 & 0.023 & $0.163(\mathrm{~ns})$ \\
\hline
\end{tabular}

Note: S is Mann - Kendall trend, P-value (two-tailed) test statistics, Slope (Sen"s slope) is the change, ns is not significant, and * represents significance trend at 0.05 significance Level.

Potential evapotranspiration

Potential Evapotranspiration (ETo) essentially comprises the simultaneous movement of water from the soil and vegetation surfaces into the atmosphere through evaporation (E) and transpiration (T) [31]. In this study, using the Mann-Kendall test, the trend of ETo for Mirab-abaya and Arbaminch stations during the period 1991 to 2018 was analyzed. The results of the application of the MK statistic test for trend identification of annual ETo were evaluated. The two had shown an increasing trend (Table 4) for A/minch Similar to average annual temperature and a decreasing trend for Mirab-abaya, the trend tests of ETo shows the statistically insignificant trend for both Mirab-abaya and Arbaminch stations (Figure 6). The magnitude of sens' slope of ETo increases to $-0.015 \mathrm{~mm} /$ year and $0.013 \mathrm{~mm} /$ year in $\mathrm{M} /$ abaya and $\mathrm{A} / \mathrm{minch}$ stations, respectively. The increasing trend of ETo is due to the increase in climatic variables and climate change. This increase in average ETo harms the present and future crop water demand. 

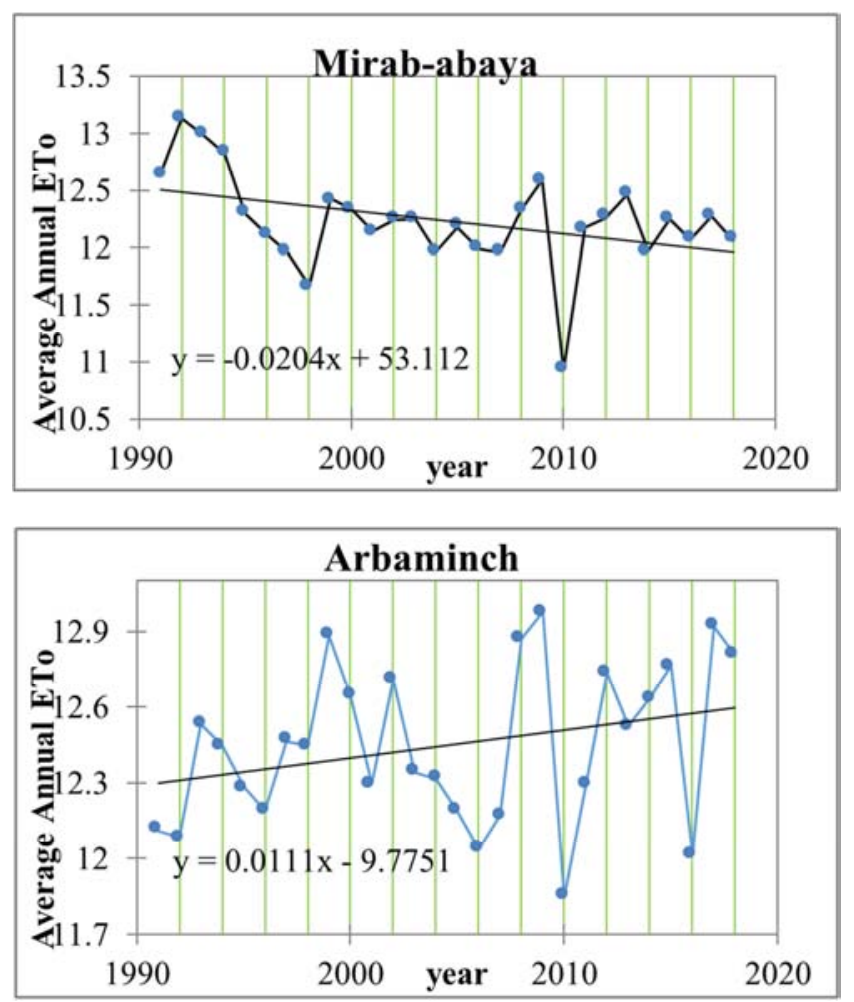

Figure 6. Observed evapotranspiration of Arbaminch and Mirab-abaya stations.

Table 4 Observed evapotranspiration.

\begin{tabular}{lllll}
\hline Station & Kendall's tau & S & p-value & Sen.'s slope \\
\hline M/abaya & -0.238 & -90.00 & $0.079(\mathrm{~ns})$ & -0.015 \\
A/minch & 0.188 & 71.000 & $0.167(\mathrm{~ns})$ & 0.013 \\
\hline
\end{tabular}

Comparison of observed and climate model output

Before using weather it is dynamically or statically downscaled climate datasets, for any hydrological or meteorological model, it is important to check its performance whether the historical or observed conditions can be replicated or not. The mean annual measured rainfall amount and dynamically downscaled model simulation output for the (1991- 2005) period were compared for this study. The fifteen-year observed average annual rainfall was about $(946.78 \mathrm{~mm})$, bias-corrected historical $(859.07 \mathrm{~mm})$, and bias- uncorrected $(343.19 \mathrm{~mm})$.

The Comparison before bias correction and after bias correction is shown in Figure 7 model simulation shows good fitness with observed monthly average data. However, the model simulation in uncorrected RCP is slightly underestimating. The statistical analysis shows a very high degree of rainfall variability presents in observed and bias-corrected datasets with the coefficient of variation ( $\mathrm{CV}=0.51$ for observed, $\mathrm{CV}=0.68$ for bias-corrected $\mathrm{RCP}$. The model simulation outputs show under biased -0.093 after correction and the model comparison with observed data shows good performance (linear relationship) with a correlation coefficient of 0.968 for bias-corrected datasets and bias correction improves the climate model simulation. The average monthly rainfall, maximum and minimum temperature graph also depicts a similar pattern with observed climate datasets as shown in Figure 7.
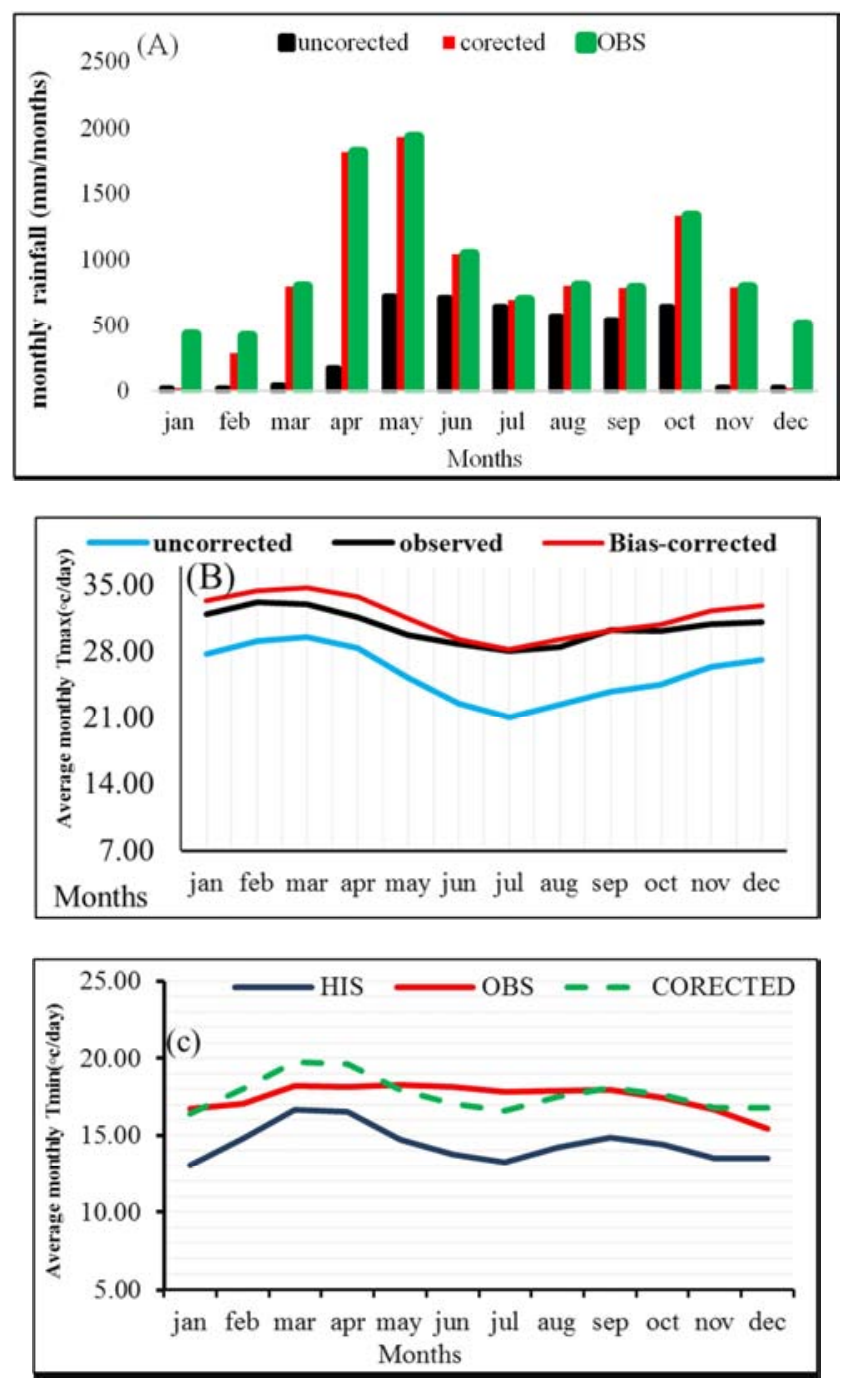

Figure 7. Comparison of average monthly rainfall (A), maximum temperature $(B)$, and minimum (C) of observed data with bias uncorrected and bias-corrected RCP datasets from (1987-2014).

However, during July and August, there is a variation of rainfall while its performance evaluation shows an acceptable range as illustrated in Table 5. This may be because at individual point regional scale predictors of rainfall variation are poorly resolved compared to temperature [28]. After correcting the bias model simulation outputs the pattern of rainfall relatively closer to the observed rainfall over the basin; this suggests the significance of bias correction

Table 5. Performance evaluation of observed vs. Historical dataset.

\begin{tabular}{llllll}
\hline & Annual RF (mm) & CV (\%) & R2 & BIAS & Correlation \\
\hline Observed & 946.78 & 0.51 & - & - & -0.093 \\
Corrected & 859.07 & 0.68 & 0.94 & 0.968 \\
Uncorrected & 343.19 & 0.89 & 0.24 & -0.638 & 0.468 \\
\hline
\end{tabular}


Trends of Future climate change under RCP scenarios

The future pattern of temperature, rainfall, and estimated evapotranspiration was analyzed under RCP4.5 and RCP8.5 scenarios for the study area. The evaluation was made in 30 years of dataset ranges: 2021- 2050 represented for analysis. The future change was calculated for each RCP scenario from the baseline (1921-2050) period for both future time frames.

Further, the annual trend also tested using Mann - Kendall trend test for each climate change in this study. Therefore, for more understanding rainfall, maximum and minimum temperature, and estimated evapotranspiration were done individually as illustrated below.

Annual Rainfall Trend

The time series of annual rainfall at the study area are shown in figure 8 , along with the linear trend lines. As presented in the figure, Trend analysis for the period of $2021-$ 2050 indicates a decreasing trend for precipitation in both the climate change scenarios of RCP 4.5 and RCP 8.5. Figure 8 shows 12-month precipitation accumulation future data from 2021 to 2050 were tested for the Mirab-abaya stations. Mann Kendall test statistic (S) indicates for the future projected precipitation shows a negative and positive trend for both the climate change scenarios (RCP8.5 and RCP4.5). The statistic

RCP 8.5 , however, is not very strongly implies that the trend is not very strong compared to RCP 4.5 . This is due to the seated goal of radiative forcing at 2100 . Sen.'s slope indicates future (2021-2050) projected rainfall decreases by $0.363 \mathrm{~mm} / \mathrm{annum}$ and $-4.103 \mathrm{~mm} /$ annum for RCP 8.5 and RCP 4.5 scenarios, for the coming 30 years. As a result, the Mann- Kendall test shows there is no more statistically significant trend at $5 \%$ significance level in Mirab-abaya stations for future projected precipitation data, In general, the trend analysis of annual precipitation indicate that there is no significant trend almost in Mirab-abaya woreda due to large Inter-annual fluctuations. For this reason, the trend evaluation indicates that there is an unstable trend almost in Mirab-abaya stations.

Table 6. Mann-Kendall test for annual precipitation data of the Mirab-abaya stations for the period of 2021-2050.

\begin{tabular}{lllll}
\hline \multicolumn{2}{l}{ Mirab-abaya } & & & \\
\hline Station & Kendall's tau & S & Sen.'s slope & p-value \\
\hline RCP 4.5 & -0.103 & -45.00 & -4.103 & $0.436(\mathrm{~ns})$ \\
RCP 8.5 & 0.051 & 22.00 & 0.363 & 0.707 (ns) \\
\hline
\end{tabular}

Note: $\mathrm{S}$ is Mann - Kendall trend, P-value (two-tailed) test statistics, Slope (Sen"s slope) is the change, ns is not significant, and * represents significance trend at 0.05 significance level.

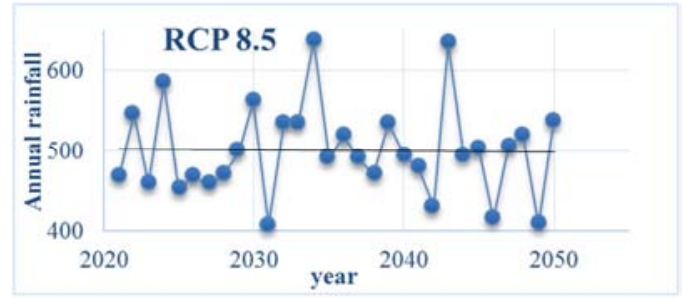

Figure 8. Projected trend of annual Rainfall for (2021-2050) under RCP4.5 and RCP8.5 Mirab-abaya

Seasonal rainfall change

Seasonal evaluation of rainfall distribution is very important for rain-fed agriculture because agricultural activity highly depends on rainfall distribution. The analysis of the seasonal distribution of rainfall is carried out considering the main seasons namely; Kiremt (June, July, August, and September); Bega (October, November, December, and January), and Belg (February, March, April, and May). The characteristics of the seasonal rainfall pattern for both RCP 4.5 and RCP 8.5 scenario in the three seasons for both 2021-2050 time term are presented in Figure below.

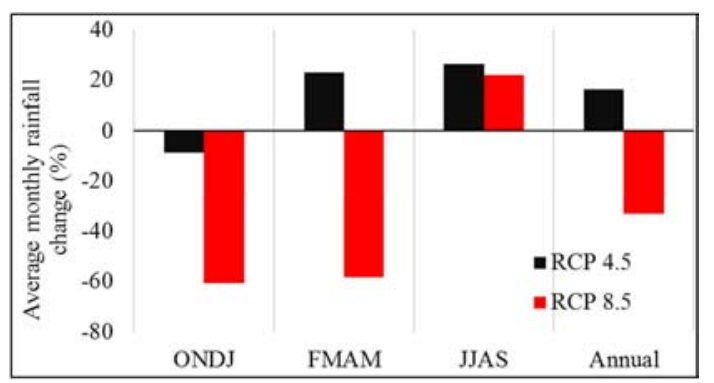

Figure 9. Projected changes of seasonal Rainfall for (2021-2050) under RCP4.5 and RCP8.5 Mirab-abaya.
The projected evaluation of future rainfall distribution over the study area decreases for Bega (ONDJ) and Belg (FMAM) under RCP 8.5 scenarios and decreases for Bega (ONDJ) under RCP 4.5, and it is expected to increase Kiremt (JJAS) under both RCP scenarios. The magnitude of positive change is better projected for Kiremt (JJAS) under both scenarios compared with the other two seasons and negative change is projected for Bega (ONDJ) under both scenarios, but also negative change is projected for Belg (FMAM) under RCP 8.5 from the baseline period. This is due to the better rainfall distribution expected in Kiremt.

Maximum temperature

The projected maximum temperature shows a distinct increase for both RCP 4.5 and RCP 8.5 scenarios. The relative change of maximum temperature from the baseline period for both scenarios in the future time horizon is shown in Figure 10. The average annual maximum temperature in (2021-2050) will be shown an increase by $0.031^{\circ} \mathrm{C}$ and $0.03^{\circ} \mathrm{C}$ /annum for RCP 4.5 and RCP 8.5 scenarios respectively. An increase for the RCP 8.5 scenario is greater than the RCP 4.5 scenario because RCP 8.5 scenario represents a high emission scenario that produces more $\mathrm{CO} 2$ concentration than the RCP 4.5 scenario which represents a low emission scenario. 


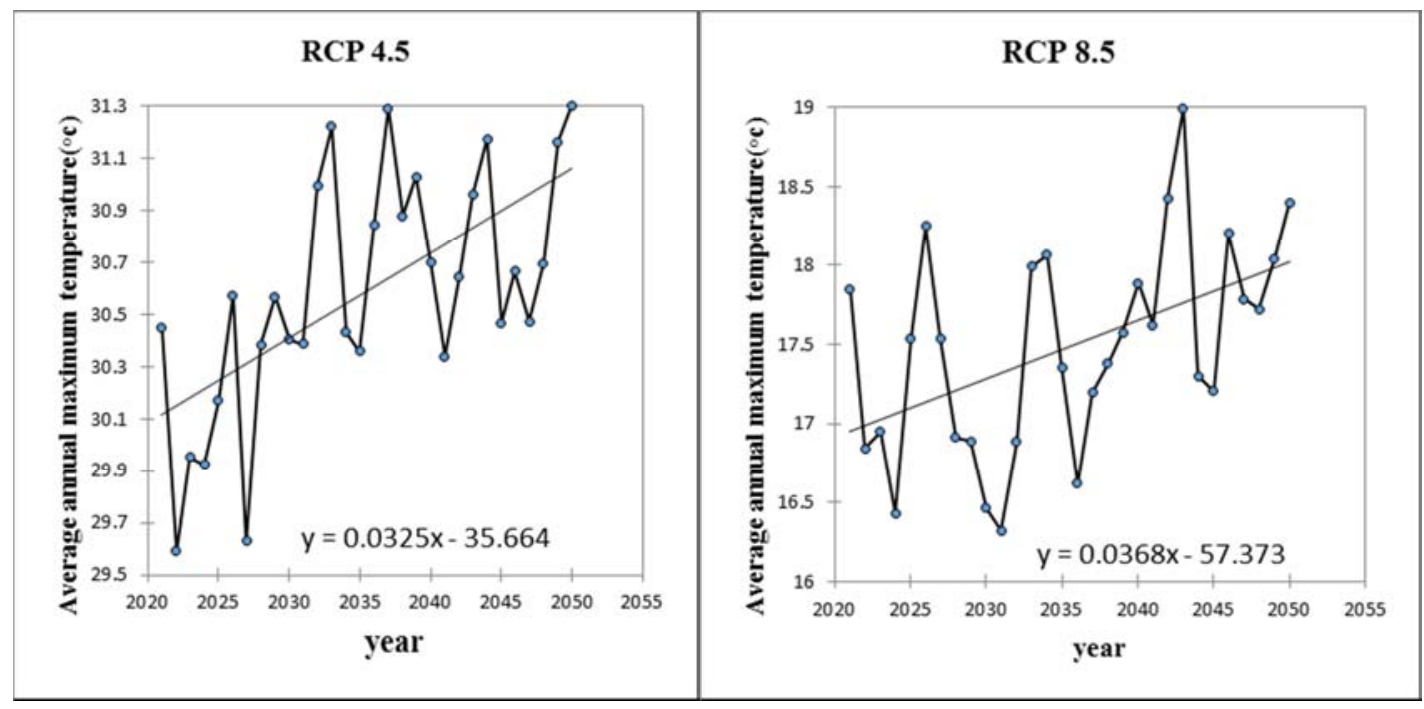

Figure 10. Annual average maximum temperature trends of both the RCP 4.5 and RCP 8.5scenarios.

The summary of Mann - Kendall test result for maximum temperature shows an increasing trend and statistically significant under both scenarios. The upward maximum temperature trends are presented in both periods under both RCP scenarios.

Table 7. MK test for average annual maximum temperature in future.

\begin{tabular}{llllll}
\hline & Scenarios & $\begin{array}{l}\text { Kendall's } \\
\text { tau }\end{array}$ & S & $\begin{array}{l}\text { Sen.'s } \\
\text { slope }\end{array}$ & P-value \\
\hline \multirow{2}{*}{ M/abaya } & RCP 4.5 & 0.44 & 193.00 & 0.031 & $0.0004^{*}$ \\
& RCP 8.5 & 0.389 & 169.00 & 0.03 & $0.002^{*}$ \\
\hline
\end{tabular}

Note: S is Mann - Kendall trend, P-value test statistics, Slope (Sen"s slope) is the change, ns is not significant, and * represents significance trend at 0.05 significance level.

The evaluation of seasonal temperature is very important for crop production because higher values above the normal temperature during cropping season harm crop production [3]. Changes in the mean climate away from current states may require adjustments to current practices to maintain productivity. In the places where the water availability is low would generally be at risk of decreasing crop yield at even 1 to $20 c$ of warming [25]. This is a result of increased

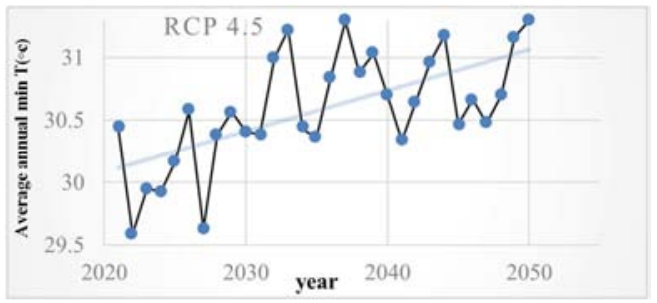

Figure 11. Annual average minimum temperature trends concerning both scenarios.

The projected minimum temperature also shows a distinct increase for both RCP 4.5 and RCP 8.5 scenarios. The average annual minimum temperature in (2021-2050) will be increased by $1.5^{\circ} \mathrm{C}$ and $3.7^{\circ} \mathrm{C}$ for RCP 4.5 and RCP 8.5 emission scenarios respectively. evapotranspiration and lower soil moisture level [2]. Hence, higher temperatures may be more immediately detrimental, increasing the heat stress on crops and water loss by evaporation and the current finding also confirms higher temperature during the growing season which can significantly impact agricultural productivity.

Table 8 shows an average seasonal change in maximum temperature in the future. Temperature is projected from high to low during Belg (FMAM), Kiremt (JJAS), and Bega (ONDJ) under both scenarios. The change from the period of (2021-2050) is concerned, it positively increases more under both scenarios for the scenarios and, but projected to decrease in Kiremt (JJAS) under both scenarios at a rate of $-0.024^{\circ} \mathrm{C}$.

Table 8. Average seasonal change in maximum temperature in the future $\left({ }^{\circ} \mathrm{c}\right)$.

\begin{tabular}{llll}
\hline RCP scenario & Belg & Kiremt & Bega \\
\hline RCP 8.5 & 0.019 & -0.023 & 0.001 \\
RCP 4.5 & 0.018 & -0.026 & 0.005 \\
\hline
\end{tabular}

Note: - (ONDJ) October, November, December, and January, (Bega) and (FMAM) February March, April and May Belg, and (JJAS) June, July, August, and September (Kiremt).

Minimum temperature

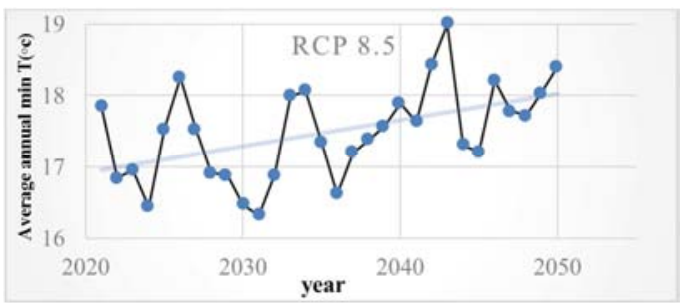

Mann- Kendall's trend and sen's slope estimates suggest that the rise of minimum temperature for both future periods and under both scenarios. Statistically significantly.

The increasing minimum temperature will be expected for both periods of scenario projections at $5 \%$ significance as 
shown in Table 9.

Table 9. $M K$ trend test and statistical summary of annual minimum temperature $\left({ }^{\circ} \mathrm{C}\right)$ per annual for 2021-2050 term projection under $R C P$ scenario in Mirab-abaya.

\begin{tabular}{llllll}
\hline & Scenarios & $\begin{array}{l}\text { Kendall's } \\
\text { tau }\end{array}$ & S & Sen.'s & P-value \\
\hline M/abaya & RCP 4.5 & 0.444 & 193.00 & 0.031 & $0.03^{*}$ \\
& RCP 8.5 & 0.338 & 147.00 & 0.04 & $0.04 *$ \\
\hline
\end{tabular}

Note: S is Mann - Kendall trend, P-value (two-tailed) test statistics, Slope (Sen"s slope) is the change, ns is not significant, and * represents significance trend at 0.05 significance level The result shows the warming trend in two seasons with higher magnitude in Belg season while less in Kiremt comparatively.

Table 10. Projected minimum temperature in terms of seasonal.

\begin{tabular}{llll}
\hline RCP scenario & Belg & Kiremt & Bega \\
\hline RCP 8.5 & 0.03 & -0.04 & 0.01 \\
RCP 4.5 & 0.04 & -0.05 & 0.005 \\
\hline
\end{tabular}

Note: - (ONDJ) October, November, December, and January, (Bega) and (FMAM) February March, April and May Belg, and (JJAS) June, July, August, and September (Kiremt).

\section{Potential Evapotranspiration}

In this study, the future potential evapotranspiration was calculated by using the Mirab-abaya station and future projected climate scenarios of (RCP 2.6 and RCP4.5). The estimated evapotranspiration for both scenarios was analyzed in terms of seasonal and annual average evapotranspiration for this study. Similar to the projected change of air temperature, increasing evapotranspiration in all months except September from the baseline period under both scenarios as shown in Figure 11 will be expected. The Mann-Kendall test shows that there is an increasing trend for the period of 2021-2050. Figure 12 shows the trend of 12-month evapotranspiration accumulation for the period of 2021-2050. The percentage change of evapotranspiration shows a higher amount under RCP 8.5 compared to RCP 4.5 for all months. In general, the climatological average of projected evapotranspiration variation shows a bimodal pattern with peaks in May and June in projection. This shows a slight shifting of the growing season with one month. It rises from March to April and rises to increase more from April to August then starts to decline in September under both scenarios.

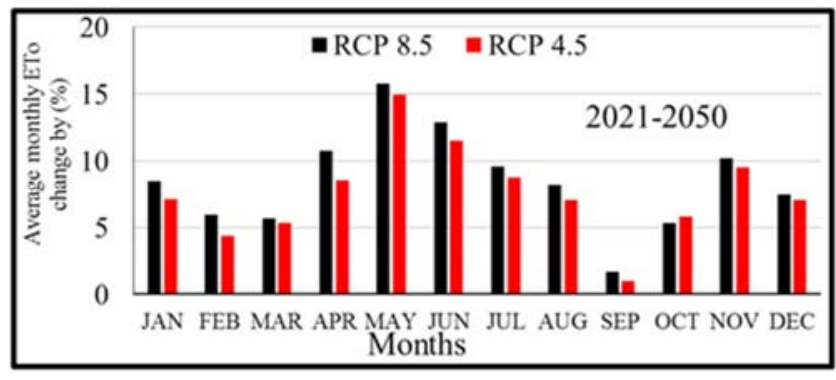

Figure 12. Projected percentage of evapotranspiration.

The seasonal projected change in evapotranspiration (ETo) for both scenarios and future time frames was presented in figure 12. The result indicates the increasing pattern of ETo for each season during both future time frames under both scenarios as shown in figure 13 .

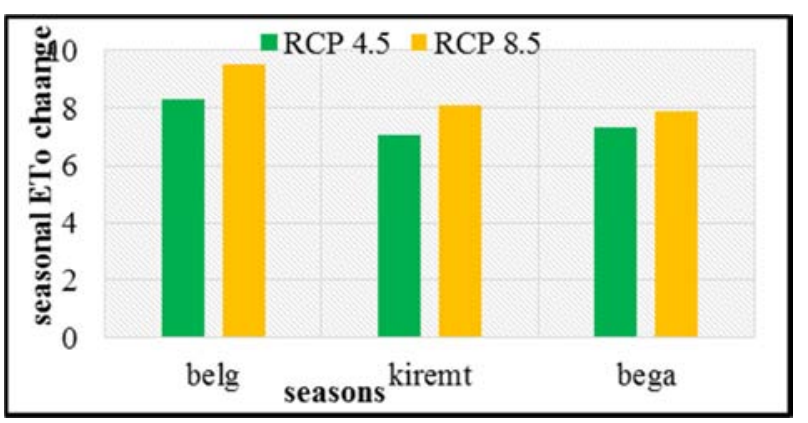

Figure 13. The seasonal projected change in evapotranspiration (ETo) for both scenarios.

Note - Bega (ONDJ) October, November, December, and January, and Belg (FMAM) February March, April, and May, and Kiremt (JJAS) June, July, August, and September.

Annual Mann- Kendall trend and sen"s slope estimates present an increasing pattern of evapotranspiration for RCP 4.5 scenario with significant change at 5\% significance level, but insignificant level for RCP 8.5 over Mirab-abaya. For both futures periods under both RCP scenarios, the trend of ETo will be suggested an upward trend in general like air temperature in Mirab-abaya. The sen"s slope estimates of the projected evapotranspiration also confirm the increasing pattern. Under both scenarios, it will be expected to rise by $0.005 \mathrm{~mm} /$ annual and $0.007 \mathrm{~mm} /$ annual for $2021-2050$ on average as presented in Table 11. Which Similar to the temperature pattern.

Table 11. MK trend test and statistical summary of annual evapotranspiration (mm/annual).

\begin{tabular}{llllll}
\hline \multirow{3}{*}{ M/abaya } & Scenarios & Kendall's tau & S & Sen.'s & P-value \\
\cline { 2 - 6 } & RCP 4.5 & 0.356 & 155.00 & 0.007 & $0.005^{*}$ \\
& RCP 8.5 & 0.246 & 107.00 & 0.005 & $0.058(\mathrm{~ns})$ \\
\hline
\end{tabular}

Note: S is Mann - Kendall trend, P-value (two-tailed) test statistics, Slope (Sen"s slope) is the change, ns is not significant, and * represents significance trend at 0.05 significance level.

\section{Crop Water Use}

Potential evapotranspiration

Crop water requirement

Results show that for maize, crop evapotranspiration (ETc) and crop water requirement varied from 2.35 to $4.64 \mathrm{~mm} /$ day and 0 to $34 \mathrm{~mm} /$ day respectively, and irrigation water requirement low at the initial stage because effective rainfall can satisfy water requirement and high at mid-stage due to minimum fall of effective rainfall (Table 13). The below table result shows that the average crop water use and irrigation water requirement of maize over Mirab-abaya. To describe the crop water use and irrigation water requirement of the study area.

Potential Evapotranspiration (ETo) of the study area was calculated by CROPWAT 8.0 software. By utilizing the meteorological data of maximum and minimum temperature, wind speed at two-meter above the surface, sunshine hour, and 
relative humidity and rainfall of the study area. The results obtained when a 28-year dataset period was used with the FAO-Penman Monteith method to determine the reference crop evapotranspiration (ETo) for the area under study, The result shows that ETo varied from a minimum value of $3.58 \mathrm{~mm} /$ day in July to the highest value of $5.18 \mathrm{~mm} /$ day in March (Table 12). The results show that ETo was lowest during the peak of the rainy season to highest during the peak of the dry season. The Current and future reference evapotranspiration over the study area is shown in Table 15.

Table 12. Reference Crop Evapotranspiration

\begin{tabular}{llll}
\hline Obs ETo & Months & Obs ETo & Months \\
\hline 4.35 & January & 3.58 & July \\
4.77 & February & 4 & August \\
5.18 & March & 4.16 & September \\
4.54 & April & 4.1 & October \\
4.32 & May & 3.82 & November \\
3.97 & June & 4.11 & December \\
\hline
\end{tabular}

Where ETo is Reference Crop Evapotranspiration computed using the FAO Penman-Monteith Method

\section{RCP 4.5}

\#ETc $\mathrm{mm} / \mathrm{dec} \equiv$ Eff rain $\mathrm{mm} / \mathrm{dec} \equiv$ Irr. Req. $\mathrm{mm} / \mathrm{dec}$

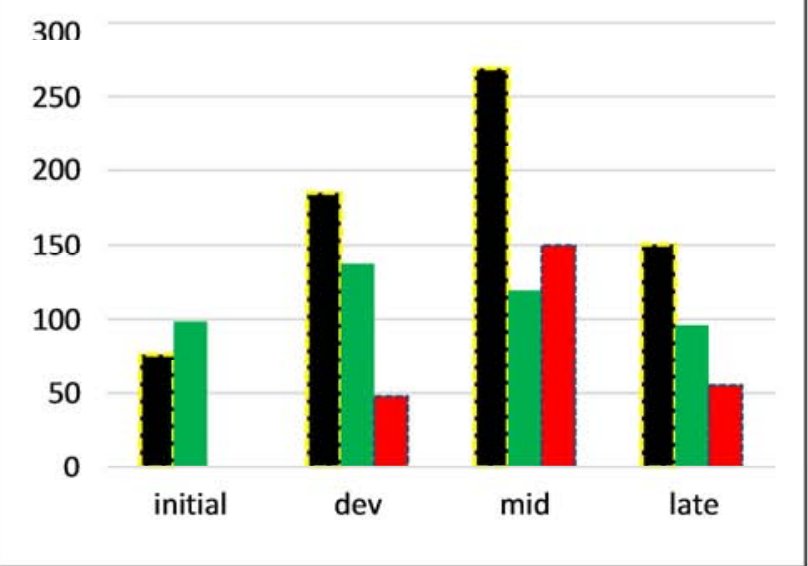

Table 13. Average crop water use and irrigation water requirement of maize.

\begin{tabular}{lllll}
\hline & Stages & $\begin{array}{l}\text { ET } \\
\text { mm/day }\end{array}$ & $\begin{array}{l}\text { Eff rain } \\
\text { mm/dec }\end{array}$ & $\begin{array}{l}\text { Irr. Req. } \\
\text { mm/dec }\end{array}$ \\
\hline \multirow{3}{*}{ observed } & initial & 9.39 & 81.7 & 0 \\
& development & 17.92 & 130.5 & 57.1 \\
& Mid & 26.22 & 100.2 & 170.8 \\
& Late & 17.02 & 84 & 69.9 \\
\hline
\end{tabular}

Water requirement for maize crop under climate change

With evapotranspiration multiplied by the time-varying crop coefficient $(\mathrm{Kc})$, the crop water requirement for maize could be obtained. However rising evapotranspiration in the future, will increase the crop water requirement during the initial and Development cropping stage in the future. Future also requests more water $34.5 \mathrm{~mm} / \mathrm{Dec}$ at initial stage more water would be needed in the future during the first stage of RCP 8.5 due to the Increase in temperature in the future and high emission of $\mathrm{CO} 2$.

Concentration, and would increase the possibility of water deficit compere with RCP4.5. If rainfall could not supply essential crop water requirements in the future the irrigation is needed. Current and future crop water use and irrigation water requirement under study area shown in Table 16.

\section{RCP 8.5}

- ETc $\mathrm{mm} / \mathrm{dec}=$ Eff rain $\mathrm{mm} / \mathrm{dec}$ Irtheq. $\mathrm{mm} / \mathrm{dec}$

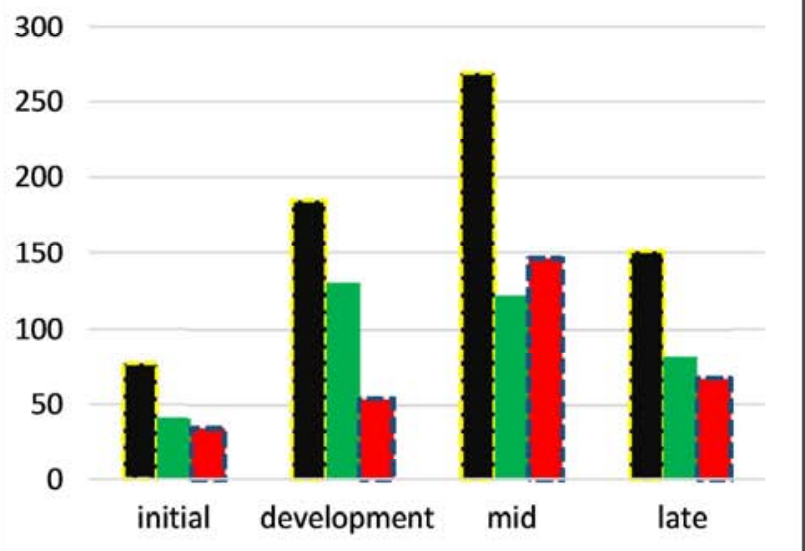

Figure 14. Projected Water and Irrigation Requirement of Maize crop.

Table 14. Result shows that the average crop water use and irrigation water requirement.

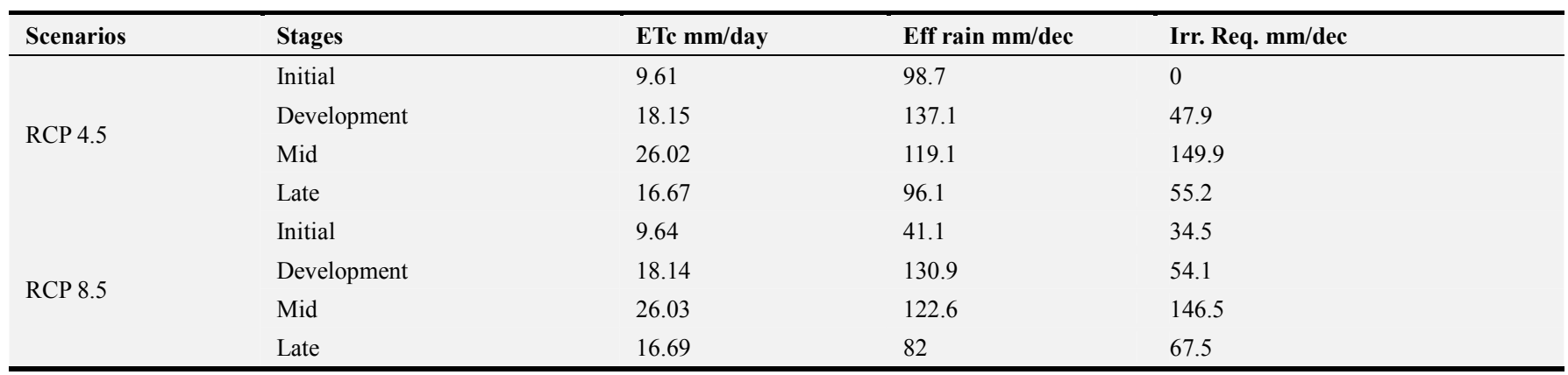

Also, as illustrated that in table 14 and figure 14 the probability distribution of crop water requirement seems to be a difference between the present and the future in the cropping season. In general, the results show that in future years the 
crop water use of maize crops will increase in the study area. The reason for this may be due to an increase in air temperature and a decrease in relative humidity in future years. Also, the average rainfall of the study area is showing a decreasing trend. Crop productivity highly depends on the surrounding climate variables like precipitation, Air temperature, and others. The result of this thesis indicates mitigation and adaptation strategy and water Harvesting are needed and recommended for cropping season to have effective production.

\section{Conclusions}

1. This study has presented analyses of recent and future rainfall and temperature trends and relationships between the change of crop water use of Maize crop under climate change using historical data obtained from meteorological stations and future climate data downscaled for the study area. The main findings of the study are summarized below

2. The annual rainfall pattern is projected to decrease in the future for RCP 4.5 and RCP 8.5 scenarios in (2021-2050). Seasonal evaluation of projected rainfall distribution in the study area shows a decreasing pattern in the Bega (ONDJ) under both RCP scenarios also decreasing trend for Belg (FMAM) RCP8.5 but increasing for Kiremt (JJAS) under both RCP scenarios and also increasing for Belg (FMAM) for the RCP4.5 scenario. Air temperature is projected to increase under both future scenarios projected from CORDEX climate projection data with a statistically significant increasing trend. The projected maximum and minimum temperature show a distinct increase for both RCP 4.5 and RCP 8.5 scenarios. The relative change of maximum and minimum temperature from the baseline period for both scenarios in future time horizon and Magnitude of temperature change projected is high under the RCP 8.5 scenario compared with 4.5 in both terms as expected. This is because, more rapid socioeconomic and population growth, with limited climate change mitigation and adaptation under the RCP8.5 climate change scenarios with high emission of $\mathrm{CO} 2$ resulting more.

3. Atmospheric forcing. Therefore, evapotranspiration calculated from minimum and maximum temperature is also projected to increase under both scenarios. A higher magnitude of evapotranspiration change is projected under RCP 8.5 with more warming trend of temperature compared to RCP 4.5. This initiates more amount of water to be evaporated from soil and plant canopy and affects plant growth and yield. The more evaporative effect causes lack of moisture in soil layers and affects plant growth, development, and yield.

4. The simulated climatic variables were used as inputs to CROPWAT to predict CWR and irrigation amounts, as the result shows irrigation water requirement is projected to increase more for mid-stage under both scenarios. The crop needs sufficient water particularly during the initial and developmental stages to obtain the maximum yield. Particularly, maize requires more water in the mid-stage. Therefore, need more irrigation during the midstage of maize development. Therefore, current and future crop water requirements with climate change and the dynamic nature of weather variables might alter the future crop water requirement study area.

5. Generally, the future Crop Water use and Irrigation water Requirement of Maize will increase in the study area. The reason for this is due to an increase in air temperature and a decrease in average rainfall in future years.

\section{Recommendation}

1. Temperature change is also increasing projection in both maximum and minimum temperature. Therefore, some climate change mitigation and adaptation strategies like planting trees, soil conservation methods are recommended for future climate change

2. Increasing in temperature and decreasing of rainfall in mirab abaya woreda lead to an increase in the rate of crop water use adding to the currently frequent water stress of crops. In response to this situation, Use supplementary irrigation (small-scale irrigation, water harvesting), and the application of soil water conservation techniques, should be applied in a study area.

3. Future Crop Water use and Irrigation water Requirement of Maize expected to increase in the study area. Therefore the need for adequate provision of irrigation, water harvesting Techniques and drainage infrastructures could be regarded as critical for climate change adaptation.

4. The output of this study is based on only a single Regional climate model (CanESM2) and Cropwat model under RCP 4.5 and RCP8.5 emission scenarios. Therefore, further study should consider the wide range of uncertainties associated with models and try to reduce these uncertainties by using different Cropwat models and multi-Regional Climate Model outputs, and emission scenarios.

5. Some parameters such as relative humidity and sunshine hours were considered to be constant throughout the simulation period; such assumption may influence maize crop water requirements projection in the Mirab Abaya woreda. In addition to this, the uncertainty of climate change was not investigated in this study. Therefore, further studies have been recommended taking into account the uncertainty of climate change and adaptation and mitigation strategies of climate in the study area. 


\section{Appendix}
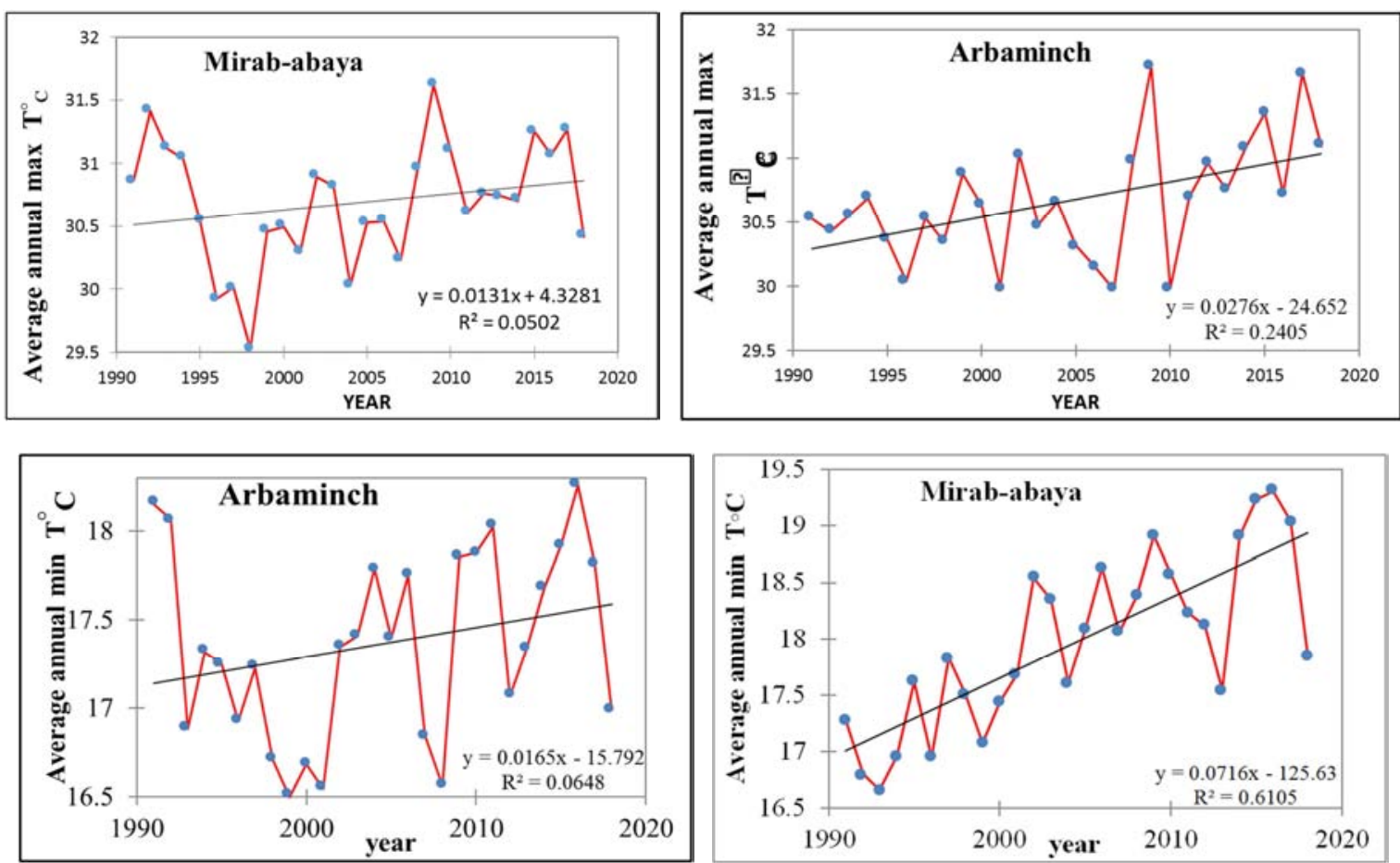

Figure 15. Observed long-term average annual Tmax and Tmin trend distribution of mirab-abaya and Arbaminch.
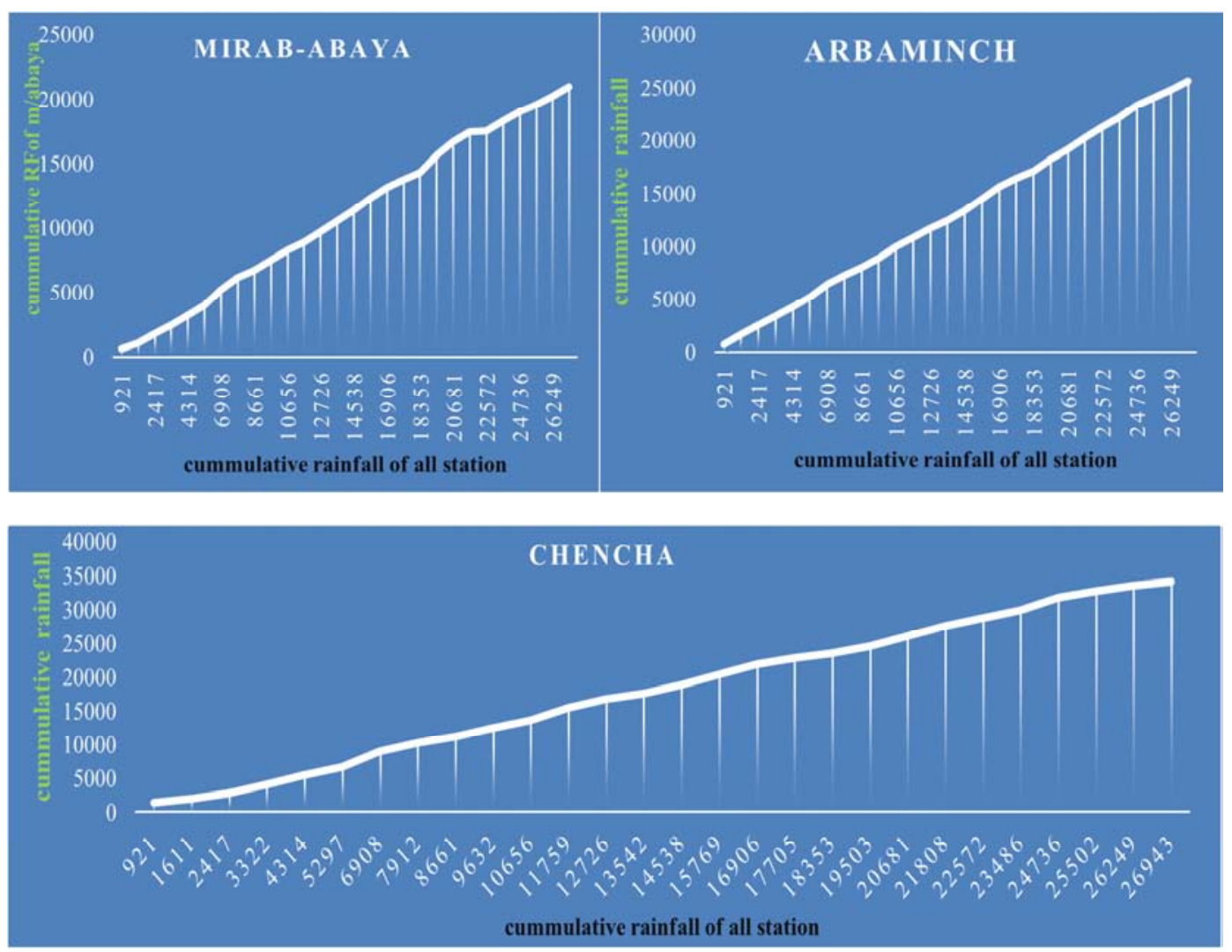

Figure 16. Consistency results of for individual meteorological stations. 

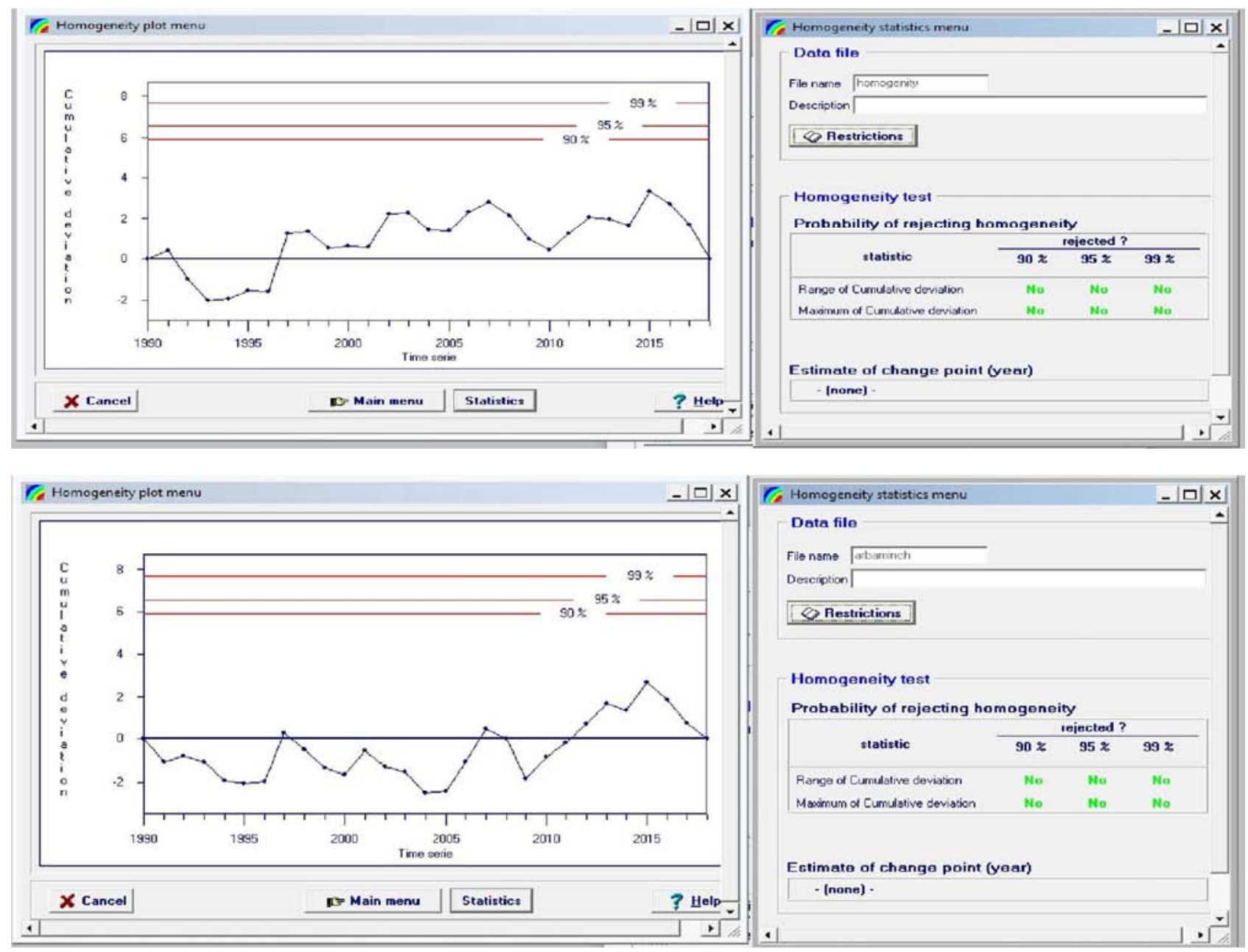

Figure 17. Homogeneity test for Chencha and Arbaminch respectively.

Table 15. Current and future reference evapotranspiration over the study area.

\begin{tabular}{llll}
\hline ETo mm/day & & & RCP 8.5 \\
\hline Month & Obs & RCP 4.5 & 4.36 \\
\hline Jan & 4.35 & 4.37 & 4.73 \\
Feb & 4.77 & 4.74 & 5.21 \\
Mar & 5.18 & 5.22 & 4.67 \\
Apr & 4.54 & 4.65 & 4.43 \\
May & 4.32 & 4.43 & 3.98 \\
Jun & 3.97 & 3.97 & 3.54 \\
Jul & 3.58 & 3.54 & 3.94 \\
Aug & 4 & 3.93 & 4.07 \\
Sep & 4.16 & 4.04 & 4.04 \\
Oct & 4.1 & 4.06 & 3.84 \\
Nov & 3.82 & 3.85 & 4.13 \\
Dec & 4.11 & 4.14 & \\
\hline
\end{tabular}

Table 16. Current and future crop water use and irrigation water requirement under study area.

\begin{tabular}{|c|c|c|c|c|c|c|c|}
\hline \multirow{2}{*}{ Month } & \multicolumn{7}{|c|}{ RCP 4.5 } \\
\hline & Decade & Stage & Kc coeff & ETc mm/day & ETc $\mathrm{mm} / \mathrm{dc}$ & Eff rain $\mathrm{mm} / \mathrm{dc}$ & Irr. Req. mm/dc \\
\hline Apr & 2 & Init & 0.7 & 3.26 & 13 & 20.8 & 0 \\
\hline Apr & 3 & Init & 0.7 & 3.2 & 32 & 44.4 & 0 \\
\hline May & 1 & Init & 0.7 & 3.15 & 31.5 & 33.5 & 0 \\
\hline May & 2 & Deve & 0.71 & 3.14 & 31.4 & 27.3 & 4.1 \\
\hline May & 3 & Deve & 0.79 & 3.38 & 37.2 & 27.4 & 9.9 \\
\hline Jun & 1 & Deve & 0.89 & 3.66 & 36.6 & 28.4 & 8.2 \\
\hline Jun & 2 & Deve & 0.98 & 3.88 & 38.8 & 27.9 & 10.9 \\
\hline Jun & 3 & Deve & 1.07 & 4.09 & 40.9 & 26.1 & 14.8 \\
\hline
\end{tabular}




\begin{tabular}{|c|c|c|c|c|c|c|c|}
\hline \multirow{2}{*}{ Month } & \multicolumn{7}{|l|}{ RCP 4.5} \\
\hline & Decade & Stage & Ke coeff & ETe mm/day & ETc $\mathrm{mm} / \mathrm{dc}$ & Eff rain $\mathrm{mm} / \mathrm{dc}$ & Irr. Req. $\mathrm{mm} / \mathrm{dc}$ \\
\hline Jul & 1 & Mid & 1.14 & 4.22 & 42.2 & 24.2 & 18 \\
\hline Jul & 2 & Mid & 1.15 & 4.08 & 40.8 & 22.5 & 18.3 \\
\hline Jul & 3 & Mid & 1.15 & 4.23 & 46.5 & 20.7 & 25.8 \\
\hline Aug & 1 & Mid & 1.15 & 4.38 & 43.8 & 18.1 & 25.7 \\
\hline Aug & 2 & Mid & 1.15 & 4.53 & 45.3 & 15.9 & 29.5 \\
\hline Aug & 3 & Mid & 1.15 & 4.58 & 50.3 & 17.7 & 32.6 \\
\hline Sep & 1 & Late & 1.11 & 4.45 & 44.5 & 20.1 & 24.4 \\
\hline Sep & 2 & Late & 0.97 & 3.91 & 39.1 & 21.6 & 17.5 \\
\hline Sep & 3 & Late & 0.82 & 3.3 & 33 & 22.7 & 10.4 \\
\hline Oct & 1 & Late & 0.67 & 2.7 & 27 & 24.1 & 2.9 \\
\hline Oct & 2 & Late & 0.57 & 2.31 & 6.9 & 7.6 & 0 \\
\hline
\end{tabular}

\begin{tabular}{|c|c|c|c|c|c|c|c|}
\hline \multirow{2}{*}{ Month } & \multirow{2}{*}{ Decade } & \multicolumn{6}{|c|}{ Observed } \\
\hline & & Stage & Ke coeff & ETc $\mathrm{mm} / \mathrm{day}$ & ETc $\mathrm{mm} / \mathrm{dec}$ & Eff rain $\mathrm{mm} / \mathrm{dec}$ & Irr. Req. $\mathrm{mm} / \mathrm{dec}$ \\
\hline Apr & 2 & Init & 0.7 & 3.18 & 12.7 & 13.5 & 0 \\
\hline Apr & 3 & Init & 0.7 & 3.13 & 31.3 & 33.8 & 0 \\
\hline May & 1 & Init & 0.7 & 3.08 & 30.8 & 34.4 & 0 \\
\hline May & 2 & Deve & 0.71 & 3.06 & 30.6 & 35.7 & 0 \\
\hline May & 3 & Deve & 0.79 & 3.32 & 36.5 & 30.9 & 5.6 \\
\hline Jun & 1 & Deve & 0.88 & 3.61 & 36.1 & 24.7 & 11.4 \\
\hline Jun & 2 & Deve & 0.97 & 3.86 & 38.6 & 20.2 & 18.4 \\
\hline Jun & 3 & Deve & 1.06 & 4.07 & 40.7 & 19 & 21.7 \\
\hline Jul & 1 & Mid & 1.14 & 4.22 & 42.2 & 17.8 & 24.4 \\
\hline Jul & 2 & Mid & 1.15 & 4.1 & 41 & 16.1 & 24.9 \\
\hline Jul & 3 & Mid & 1.15 & 4.26 & 46.9 & 16.3 & 30.6 \\
\hline Aug & 1 & Mid & 1.15 & 4.42 & 44.2 & 16.5 & 27.6 \\
\hline Aug & 2 & Mid & 1.15 & 4.58 & 45.8 & 16.5 & 29.3 \\
\hline Aug & 3 & Mid & 1.15 & 4.64 & 51 & 17 & 34 \\
\hline Sep & 1 & Late & 1.1 & 4.53 & 45.3 & 17.3 & 28 \\
\hline Sep & 2 & Late & 0.96 & 4 & 40 & 17.6 & 22.4 \\
\hline Sep & 3 & Late & 0.82 & 3.38 & 33.8 & 19.5 & 14.3 \\
\hline Oct & 1 & Late & 0.67 & 2.76 & 27.6 & 22.3 & 5.2 \\
\hline Oct & 2 & Late & 0.57 & 2.35 & 7.1 & 7.3 & 0 \\
\hline
\end{tabular}

\begin{tabular}{|c|c|c|c|c|c|c|c|}
\hline \multirow{2}{*}{ Month } & \multicolumn{7}{|l|}{ RCP 8.5 } \\
\hline & Decade & Stage & Ke coeff & Etc $\mathbf{m m} / \mathbf{d a y}$ & Etc $\mathrm{mm} / \mathrm{dec}$ & Eff rain $\mathrm{mm} / \mathrm{dec}$ & Irr. Req. mm/dec \\
\hline Apr & 2 & Init & 0.7 & 3.27 & 13.1 & 4.3 & 7.7 \\
\hline Apr & 3 & Init & 0.7 & 3.21 & 32.1 & 15.4 & 16.7 \\
\hline May & 1 & Init & 0.7 & 3.16 & 31.6 & 21.4 & 10.1 \\
\hline May & 2 & Deve & 0.71 & 3.14 & 31.4 & 26.4 & 5 \\
\hline May & 3 & Deve & 0.79 & 3.38 & 37.2 & 26.3 & 10.9 \\
\hline Jun & 1 & Deve & 0.89 & 3.66 & 36.6 & 26.1 & 10.5 \\
\hline Jun & 2 & Deve & 0.98 & 3.88 & 38.8 & 26.8 & 12.1 \\
\hline Jun & 3 & Deve & 1.07 & 4.08 & 40.8 & 25.3 & 15.6 \\
\hline Jul & 1 & Mid & 1.14 & 4.21 & 42.1 & 23.5 & 18.6 \\
\hline Jul & 2 & Mid & 1.15 & 4.08 & 40.8 & 22.3 & 18.5 \\
\hline Jul & 3 & Mid & 1.15 & 4.23 & 46.5 & 21 & 25.5 \\
\hline Aug & 1 & Mid & 1.15 & 4.38 & 43.8 & 19.4 & 24.4 \\
\hline Aug & 2 & Mid & 1.15 & 4.54 & 45.4 & 18 & 27.4 \\
\hline Aug & 3 & Mid & 1.15 & 4.59 & 50.5 & 18.4 & 32.1 \\
\hline Sep & 1 & Late & 1.11 & 4.47 & 44.7 & 19.2 & 25.4 \\
\hline Sep & 2 & Late & 0.97 & 3.93 & 39.3 & 19.6 & 19.7 \\
\hline Sep & 3 & Late & 0.81 & 3.31 & 33.1 & 18.8 & 14.3 \\
\hline Oct & 1 & Late & 0.66 & 2.69 & 26.9 & 18.8 & 8.1 \\
\hline Oct & 2 & Late & 0.57 & 2.29 & 6.9 & 5.6 & 0 \\
\hline
\end{tabular}

\section{Acknowledgements}

I would like to express our sincere gratitude to our advisors Mr. Amba Shalishe and Kalkidan Mulu for their invaluable assistance, professional guidance and comments from the commencement of the thesis preparation up to the end of the study.

I would also like to acknowledge National Meteorological service Agency for giving necessary meteorological data to fulfill this thesis.

Last but not least gratitude goes to my classmate Mr. Edilu muleata and Alemie Kasahun for their support and giving advice without tiring and sprouting. I would like to express 
our special and sincere appreciation to all instructors of our Department and thanks to faculty of meteorology and hydrology

\section{References}

[1] Allen, R. G., Pereira, L. S., Raes, D., Smith, M. 1998: Crop evapotranspiration - Guidelines for computing crop water requirements - FAO Irrigation and drainage paper 56. FAO Food and Agriculture Organization of the United Nations, Rome, Italy.

[2] Bals, C., Harmeling, S., and Windfuhr, M., (2008). Climate change Food security and the right to adequate food. Diakonie Katastrophenhilfe, Brot fueredie wet and Germanwatch Stuttgart, Germany.

[3] Battisti, D. S., Naylor, R. L., 2009. Historical warnings of future food insecurity with unprecedented seasonal heat. Science 323, 240-244.

[4] Befekadu Degefe and Berhanu Nega (eds), 2000. Annual Report on the Ethiopian Economy, 1999/2000. Addis Ababa: Ethiopian Economic Association.

[5] Bewket, W., 2008. Rainfall variability and agricultural vulnerability in the Amhara region, Ethiopia. Ethiopian Journal of Development Research 29, 1-34.

[6] Bishaw, Y., 2012. Evaluation of Climate Change Impact on Omo Gibe Basin (Case Study of Gilgel Gibe III Reservoir), MSc thesis, Addis Ababa.

[7] Clarke, 2007. Scenarios of Greenhouse Gas Emissions and Atmospheric Concentrations, Washington, 7 DC. USA: s.n.

[8] Cline, W., 2007. Global Warming and Agriculture. Centre for Global Development, USA.

[9] CSA (central statistical authority) (2015) Agricultural sample survey report on area and production for major crops (private peasant holdings Meher season) for 2007/08. The Federal Democratic Republic of Ethiopia. Statistical Bulletin 278, Addis Ababa, Ethiopia.

[10] David D. Houghton 2002 and WMO-No. 926. Introduction to climate change: lecture notes for meteorologists; world meteorological organization, p. 13-15.

[11] Demeke, Keil \& Zeller, 2011. Using panel data to estimate the effect of rainfall shocks on small holders' food security and Vulnerability in rural Ethiopia. Climatic Change, Volume 108, pp. 185-206.

[12] Drapela, K., Drapelova, I. (2011). Application of MannKendall test and sen"s slope estimates for trend detection in deposition data from Beskydy Mts; the Czech Republic 19972010. Beskdy Mendel University in Brno, 133-146.

[13] Food and Agricultural Organization (FAO) (2002). Irrigation mannual: planning, Development monitoring and evaluation of irrigated agriculture with farmer participation, Volume Two Module7.

[14] Food and Agriculture Organization of the United Nations (FAO). 2007. Adaptation to Climate Change in Agriculture, Forestry, and Fisheries: Perspective, Framework, and Priorities. FAO, Rome, Italy.
[15] Food and Agriculture Organization (FAO) 1992. CROPWAT: A Computer Program for Irrigation Planning and Management, by M. Smith. FAO Irrigation and Drainage Paper No. 46. Rome.

[16] Food and Agriculture Organization of the United Nations FAO, 2006. The State of Food Insecurity in the World. Rome, Italy

[17] Fransen, S. and Kusch minder, K, 2009. Migration in Ethiopia: History, Current Trends, and Future Prospects. Paper Series: Migration and Development, Country Profiles, Maastricht University.

[18] Fujino, 2006. Multi-gas mitigation analysis on stabilization scenarios using AIM global model. Multi-gasMulti-gas Mitigation and Climate Policy. The Energy Journal, Issue 3 (Special Issue).

[19] Dr. Falguni Parekh, Kevin Pramodchandra Prajapati, 2013. Climate change impacts crop water requirements for the sukhi reservoir project.

[20] Gardner FP, Pearce RB, Mitchell RL, 1985. Physiology of crop plants. Iowa State University Press, Ames (IA), USA

[21] Gebrie, G. S. \& Engida, A. N, 2015. Climate Modeling of the Impact of Climate Change on Sugarcane and Cotton for Project on 'a Climate Resilient Production of Cotton and Sugar in Ethiopia', Addis Ababa, Ethiopia: Ethiopia Development Research Institute.

[22] Gilbert, R. O. (1987). Statistical Methods for Environmental Pollution Monitoring, Van Nostrand Reinhold, New York, NY, ISBN 0- 442- 23050- 8.

[23] Haileyesus, Belay, 2011. Evaluation of Climate Change impacts on hydrology on selected Catchments of Abbay Basin. 2011

[24] Hargreaves, G. L., Hargreaves, G. H., and Riley, J. P.: Irrigation water requirements for Senegal River basin, J. Irrig. Drain. Eng., 111, 265-275, 1985.

[25] Hanson, J. D., Liebig, M. A., Merrill, S. D., Tanaka, D. L., Krupinsky, J. M., Scott, D. E. 2007. Dynamic cropping systems: increasing adaptability amid an uncertain future. Agronomy Journal. 99 pp. 939-943.

[26] Hashmi, M. Z., Shamseldin, A. Y., Melville, B. W. 2011. Comparison of SDSM and LARS-WG for simulation and downscaling of extreme precipitation events in a watershed. Stochastic Environmental Research and Risk Assessment. 25 (4) pp. 475-484.

[27] Hibbard, Meehl, Cox \& Friedlingstein, 2007. A strategy for climate change stabilization experiments. Volume Eos 88, p. 217-221.

[28] IPCC (2007) Climate Change 2007. - Impacts, Adaptation, and Vulnerability: Working Group II Contribution to the Fourth Assessment Report of the Intergovernmental Panel on Climate Change (IPCC). Cambridge: Cambridge University Press.

[29] IPCC 2012 managing the risks of extreme events and disasters to advance Climate change adaptation. In: Field CB, Barros V, Stocker TF, Qin D, Dokken DJ, Ebi KL, Mastrandrea MD, Mach KJ, Plattner GK, Allen SK, Tignor M, Midgley PM (eds) A special report of working groups I and II of the intergovernmental panel on climate change. Cambridge University Press, Cambridge, p 582. 
[30] IPCC (2014). Climate Change: Synthesis Report. Contribution of Working Groups I, II and III to the Fifth Assessment Report of the Intergovernmental Panel on Climate Change [Core Writing Team, R. K. Pachauri and L. A. Meyer (eds.)]. IPCC, Geneva, Switzerland.

[31] Kassam, A. and Smith, M. 2001. FAO Methodologies on crop water use and crop water productivity. United Nations Food and Agriculture Organization (FAO) Paper No. CWP-M07. Expert meeting on crop water productivity. Rome, Italy. Availableat: http://www.fao.org/AG/AGL/aglw/cropwater/docs/method.pdf. Accessed on September 8, 2006.

[32] Kassie Ts. 2014. Climate variability and change in Ethiopia: Exploring impacts and Adaptation options for cereal production. Phd Thesis, Wageningen University, Netherlands.

[33] Lafon, T., Dadson, S., Buys, G., and Prudhomme, C.: Bias correction of daily precipitation simulated by a regional climate model: a comparison of methods, Int. J. Climatol., 33, 13671381,2013

[34] Leander, R., and Buishand, T. A., (2007). Resampling of Regional Climate Model for the Simulation of Extreme River. Hydrology. 487-498.

[35] Mall RK, Gupta A, Singh R, Singh RS, Rathore LS (2006) Water resources and climate change: an Indian perspective. Curr Sci 90 (12): 1610-1626.

[36] Mesay M, Mohamed K, Mengesha Je, Begna B. Dino A, Aliyi $\mathrm{K}, 2018$. Characterizing intra-seasonal rainfall variability and its implications on crop production in the bale zone, southeastern Ethiopia, p. 5.

[37] McCuen, Richard H. (1998). Hydrologic Analysis and design. Second edition, ISBN0- 13-134958-9. United States of America.

[38] Muamba F, Kraybill D, Orindiet and Stigeet 2010. Weather Vulnerability, Climate Change, and Food Security in Mt. Kilimanjaro. The poster was prepared for presentation at the Agricultural \& Applied Economics Association 2010 AAEA, CAES, \& WAEA Joint Annual Meeting. Denver, Colorado, July $25-27,2010$

[39] Montiee H., McBean E. (2009). An assessment of long term trends in hydrological components and implication for water levels in Lake Superior. Hydrology Research, 564-579.

[40] Onoz \& Bayazit, 2012. The Power of Statistical Tests for Trend Detection. Turkish Journal of Engineering \& Environmental Sciences, Volume 27, p. 247-251.

[41] Riahi, Gruebler \& Nakicenovic, 2007. Scenarios of long-term socio-economic and environmental development under climate stabilization. Technological Forecasting and Social Change, Volume 74, 7, pp. 887-935.

[42] Seaby, L. P., Refsgaard, J. C., Sonnenborg, T. O., Stisen, S., Christensen, J. H., \& Jensen, K. H. (2013). Assessment of robustness and significance of climate change signals for an ensemble of distribution-based scaled climate projections. Journal of Hydrology 486 (0), 479-493.

[43] Singh V. P. 1994 Elementary Hydrology. Prentice Hall of India, New Delhi.

[44] Stone \& Knutti, 2011. Weather and climate. In Modelling the Impact of Climate Change on Water Resources. Fai Fung, Ana Lopez and Mark New, (eds). Blackwell Publishing.

[45] Tabari, H., Maroti, S., Aeini, A., Talaee, P. H., Mohammadi, K. (2011). Trend analysis of reference evapotranspiration in the western half of Iran. Agricultural and Forest Meteorology, 128136.

[46] Terink. W., Hurkmans, R., Torfs, P., and Len, G., (2010). Evaluation of bias correction methods Applied to downscaled Precipitation and Temperature reanalysis data for a basin. Hydrology. Earth System Science.

[47] Thomas, T., Jaiswal, R., Galkate, R., Singh, S. (2009). Development of a rainfall - recharge relationship for a fractured basaltic aquifer in central India. Water Resour. Manag. 31013139 .

[48] Thornton, P. K., Jones, P. G., Owiyo, T. M., Kruska, R. L., Herrero, M., Kristjanson, P., Kelkar, U., 2006. Mapping climate vulnerability and poverty in Africa: Report to the Department for international development. ILRI, Nairobi, Kenya.

[49] UNFCCC, 2007. Climate change: impacts, vulnerabilities, and adaptation in developing countries. Climate Change Secretariat (UNFCCC). 68 pp. Bonn, Germany.

[50] UNEP, 2009. Rainwater Harvesting a Lifeline for Human Will-being a. Report Prepared Stockholm Environment Institute.

[51] World Bank, 2006. Managing water resources to maximize sustainable growth: A country water resources assistance strategy for Ethiopia. World Bank, Washington, DC.

[52] WMO (World Meteorological Organization), 1988. Analyzing long time series of hydrological Data with respect to climate variability. WCAP-3, WMO/TD No. 224. World Bank, 2006. Managing water resources to maximize sustainable growth: A country water resources assistance Strategy for Ethiopia. World Bank, Washington, DC.

[53] Yihun, D, 2009. Hydrological Modeling to Assess Climate Change Impact at Gilgel Abay River, Lake Tana Basin Ethiopia: Division of Water Resources Engineering Master's Program.

[54] Yue, S., and Wang. P. (2004). A comparison of a power of the $t$ test, Mann- Kendall and bootstrap tests for trend detection. Hydrological Science Journal, 21-37.

[55] Zeray, L, 2006. Climate Change Impact on Lake Ziway Watershed Water Availability, Ethiopia. MSc. Cologne: University of Applied Sciences Cologne, Institute for Technology in the tropics. 